\title{
CRESCIMENTO E ESTADO NUTRICIONAL DE MUDAS DE CITROS INFLUENCIADAS PELA ADUBAÇÃO COM NITROGÊNIO, FÓSFORO, POTÁSSIO E CÁLCIO
}

JONAS RUSCHEL

Engenheiro Agrônomo

Orientador: Prof. Dr. QUIRINO AUGUSTO DE CAMARGO CARMELLO

Tese apresentada à Escola Superior de Agricultura "Luiz de Queiroz", Universidade de São Paulo, para obtenção do título de Doutor em Agronomia, Área de Concentração: Solos e Nutrição de Plantas.

PIRACICABA

Estado de São Paulo - Brasil

Setembro - 2002 
ERRATA

\begin{tabular}{|c|c|c|}
\hline Página e linha: & onde se lê: & leia-se: \\
\hline página viii, linha 4 & determinar-se & determinar \\
\hline página viii, linha 5 & proporcionavam & proporcionassem \\
\hline página viii, linha 7 & does & doses \\
\hline página viii, linha 10 & rendimax & $\begin{array}{l}\text { composto por vermiculita, perlita, casca } \\
\text { de pinus e material orgânico }\end{array}$ \\
\hline página viii, linha 14 & produções de produções de & produções de \\
\hline página ix, linha 7 & determinar-se & determinar \\
\hline página ix, linha 13 & rendimax & $\begin{array}{l}\text { composto por vermiculita, perlita, casca } \\
\text { de pinus e material orgânico }\end{array}$ \\
\hline página ix, linha 22 & A concentração & As concentrações \\
\hline página 2 , linha 19 & culturas & plantas \\
\hline página 4 , linha 5 & grapefruits e pomelos & grapefruits ou pomelos \\
\hline página 6 , linha 3 & à doença & à doenças \\
\hline página 7 , linha 1 & Baianinha & 'Baianinha' \\
\hline página 8 , linha 8 & radical & radicular \\
\hline página 11 , linha 27 & verificou & verificaram \\
\hline página 12 , linha 9 & "Cravo" & 'Cravo' \\
\hline página 17 , linha 11 & coletado & coletadas \\
\hline página 18 , linha 26 & estudas & estudadas \\
\hline página 32 , linha 1 & as & às \\
\hline página 34 , linha 7 e 8 & são aos 4 meses & foram determinadas aos 4 meses \\
\hline página 35 , linha 4 & onde & na qual \\
\hline página 36 , linha 1 & obtido & obtida \\
\hline página 38 , linha 3 & obtido & obtida \\
\hline página 40 , linha 1 & são & é \\
\hline página 43, linha 6 & obteve & obtiveram \\
\hline página 43 , linha 12 & máxima & máximo \\
\hline
\end{tabular}


Dados Internacionais de Catalogação na Publicação (CIP)
DIVISÃO DE BIBLIOTECA E DOCUMENTACCAO - ESALO/USP

Ruschel, Jonas

Crescimento e estado nutricional de mudas de citros influenciadas

pela adubação com nitrogênio, fósforo, potássio e cálcio / Jonas Ruschel.

- Piracicaba, 2002.

$69 \mathrm{p}$.

Tese (doutorado) - - Escola Superior de Agricultura Luiz de Queiroz, 2002.

Bibliografia.

1. Adubação 2. Cálcio 3. Crescimento vegetal 4. Estufas 5. Fertilizantes NPK 6. Limão 7. Porta-enxertos I. Título

CDD 634.334

\section{Termitida a copia total ou parcial deste documento, desde que citada a fonte - 0 autor:}


“ Não basta ensinar ao homem uma especialidade. Porque se tornará uma máquina utilizável, mas não uma personalidade.

É necessário que adquira um sentimento daquilo que é belo, do que é moralmente correto.

A não ser assim, ele se assemelhará, com seus conhecimentos profissionais, mais um a cão ensinado do que uma criatura harmoniosa e desenvolvida.

Deve aprender a compreender as motivações dos homens, suas quimeras e suas angústias, para determinar com exatidão seu lugar em relação a seus próximos e à comunidade."

\section{Albert Einstein}

Ao Criador por me guiar e acompanhar em tudo que faço, Agradeço.

Aos meus pais, Pedro e Elvira, poderosos motivadores para a luta contínua,

Ofereço.

À Luciana Kolm, companheira, esposa, amiga, incentivadora e porto seguro a cada volta das contínuas ausências que a missão me destina,

Dedico. 


\section{AGRADECIMENTOS}

Ao Prof. Dr. Quirino Augusto de Camargo Carmello pela amizade, orientação e apoio, que contribuíram para a realização deste trabalho.

Aos Drs. Sérgio Alves de Carvalho e Alberto Carlos de Campos Bernardi, pelas sugestões e apoio para a realização deste trabalho.

Ao Dr. Dirceu Mattos Júnior, pelas sugestões e pela auxílio na confecção e correção do "summary".

Ao Centro Avançado de Pesquisa Tecnológica do Agronegócio de Citros "Sylvio Moreira" (IAC) pela infra-estrutura e pelo apoio durante a condução dos experimentos.

À Fundação de Amparo à Pesquisa no Estado de São Paulo (FAPESP), pelo apoio financeiro através da Bolsa concedida.

Aos funcionários do Setor de Nutrição Mineral de Plantas da ESALQ/USP: Edinéia Cristina S. Mondoni, Lurdes A. Dário de González, Lúcia Helena S. Pavan Forti, Nivanda Maria de Moura, e Sueli Maria Amaral Campos Bovi, pela amizade e pelo auxílio prestado na condução do estudo e na realização das análises químicas.

Às Bibliotecárias Eliana Maria Garcia Sabino e Silvia Zinsly pela correção das referência bibliográficas.

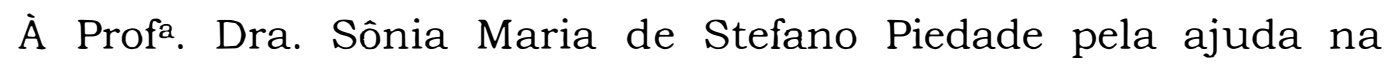
interpretação das análises estatísticas.

Aos colegas Antônio Sampaio Baptista, Cristiaine Kano, Edna Maria da Silva Bonfim, Ivan André Alvarez, Glaucia Regina Anti e Reges 
Heinrichs pela amizade e pelo grande auxilio prestado para a realização deste trabalho.

Aos colegas da sala de Pós-graduação do Setor de Nutrição Mineral de Plantas da ESALQ/USP pela amizade, pelas sugestões no estudo e pelas experiências de vida transmitidas.

A todas as pessoas que não foram mencionadas mas que auxiliaram de alguma forma para que este trabalho pudesse ser realizado com êxito. 


\section{SUMÁRIO}

Página

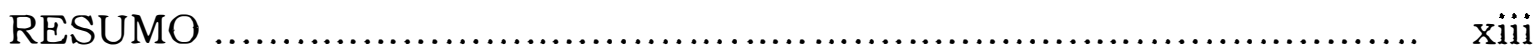

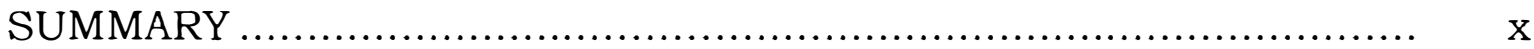

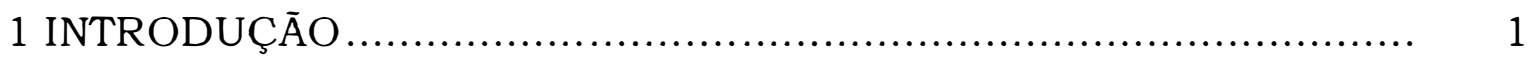

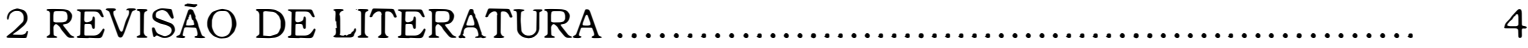

2.1 Considerações gerais.................................................... 4

2.2 Nitrogênio, fósforo, potássio e cálcio em citros ........................... 5

2.3 Produção de mudas de citros em vasos .................................. 7

2.4 Nutrição mineral e balanço de carboidratos............................. 9

2.5 Adubação das mudas de citros ............................................ 10

3 MATERIAL E MÉTODOS ................................................. 14

3.1 Local de condução dos experimentos................................ 14

3.2 Delineamentos experimentais e tratamentos .......................... 16

3.3 Instalação e condução..................................................... 17

3.4 Avaliações ........................................................... 17

3.5 Análises estatística ........................................................ 18

4 RESULTADOS E DISCUSSŌES ........................................ 20

4.1 Produção de material seco ............................................. 20

4.2 Altura das plantas, diâmetro do caule, concentração de carboidratos solúveis totais, volume das raizes e área foliar ...... $\quad 25$

4.3 Concentrações foliares .................................................. 30 


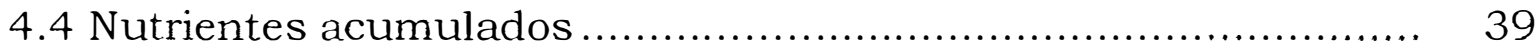

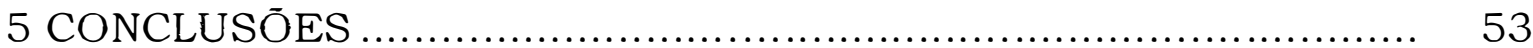

REFERÊNCIAS BIBLIOGRÁFICAS ................................. 54

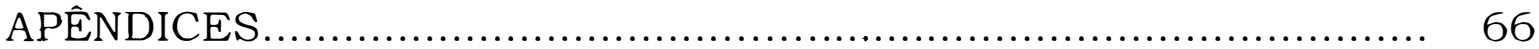




\section{CRESCIMENTO E ESTADO NUTRICIONAL DE MUDAS DE CITROS INFLUENCIADAS PELA ADUBAÇÃO COM NITROGÊNIO, FÓSFORO, POTÁSSIO E CÁlCIO}

Autor: JONAS RUSCHEL Orientador: Prof. Dr. QUIRINO AUGUSTO DE CAMARGO CARMELLO

\section{RESUMO}

Foram conduzidos dois experimentos com o objetivo de avaliar a produção de porta-enxerto e de mudas de citros em resposta à adubação com $\mathrm{N}, \mathrm{P}, \mathrm{K}$ e $\mathrm{Ca}$, em ambiente protegido. O primeiro experimento objetivou determinar-se a melhor combinação das doses NPKCa, que proporcionavam uma nutrição adequada do porta-enxerto limoeiro 'Cravo'. Utilizou-se um fatorial fracionado $(1 / 25) 5^{4}$, com 4 niveis de nutrientes ( $\mathrm{N}, \mathrm{P}, \mathrm{K}$ e $\mathrm{Ca}$ ) e cinco does, num total de 25 tratamentos, repartidos em 5 blocos de 5 tratamentos. As mudas do limoeiro 'Cravo' foram transplantados com $10 \mathrm{~cm}$, para os vasos $\left(3,8 \mathrm{dm}^{3}\right)$ com substrato rendimax. Os tratamentos (g por planta) foram: $\mathrm{N}(0,31 ; 0,62 ; 1,25 ; 2,5$ e 5), $\mathrm{K}(0,4 ; 0,62 ; 1,25 ; 2,5$ e 5), P $(0,35 ; 1,0 ; 2,0 ; 3,0$ e 4,0) e Ca $(3,5$; $5,0 ; 6,0 ; 7,0$ e 8,0$)$. As fontes utilizadas para os tratamentos foram nitrato de amônio, superfosfato triplo, cloreto de potássio e gesso agricola. Avaliou-se as produções de produções de material seco das 
folhas, caule, raizes e total da planta, altura das plantas, volume de raizes, diâmetro do caule, concentração total de nutrientes e de carboidratos solúveis totais nas folhas e o acúmulo de nutrientes. Funções de respostas foram ajustadas aos niveis de nutrientes, para se obter as melhores respostas. Concluiu-se que, para a produção dos porta-enxertos, as doses mais adequadas foram $\mathrm{N}=3,5 ; \mathrm{P}=2,7 ; \mathrm{K}=2,0$ e $\mathrm{Ca}=6,5 \mathrm{~g}$ por planta. $\mathrm{O}$ segundo experimento objetivou determinar-se a melhor combinação das doses $\mathrm{NKCa}$ que proporcionavam uma nutrição adequada à laranjeira 'Pêra'. Utilizou-se um fatorial fracionário $(1 / 5) 5^{3}$, com 25 tratamentos, repartidos em 5 blocos de 5 tratamentos. A laranjeira 'Pêra' foi enxertada sobre o porta-enxerto limoeiro 'Cravo' aos quatro meses após o transplante para vasos $\left(3,8 \mathrm{dm}^{3}\right)$ contendo substrato rendimax. Após o pegamento da enxertia iniciou-se a aplicação dos tratamentos. Os tratamentos (g por planta) foram: $\mathrm{N}(0,37$; $0,75 ; 1,50 ; 3,0$ e 6,0$)$, K $(0,37 ; 0,75 ; 1,50 ; 3,0$ e 6,0$)$ e Ca $(0,6 ; 1,8 ; 3,0$; $4,2$ e 5,4$)$. O P $(2,7 \mathrm{~g}$ por planta). As fontes utilizadas para os tratamentos foram $\mathrm{NH}_{4} \mathrm{NO}_{3}, \mathrm{KCl}$ e $\mathrm{Ca} \mathrm{Cl}_{2}$. Avaliou-se as produções de material seco das folhas, caule, raizes, total da parte aérea e total da planta, volume de raizes, diâmetro do caule, altura, área foliar, concentração total de nutrientes e de carboidratos solúveis totais nas folhas e acúmulo de nutrientes. Coletou-se as plantas aos 6 meses de idade. A concentração de carboidratos solúveis totais nas folhas não tiveram efeito significativo em função dos tratamentos. Concluiu-se que as doses que proporcionaram uma nutrição mais equilibrada para a muda foram $\mathrm{N}=5,0 ; \mathrm{K}=2,0$ e $\mathrm{Ca}=5,0 \mathrm{~g}$ por planta. 


\title{
GROWTH AND NUTRITIONAL STATUS OF CITRUS PLANTS AS AFFECTED BY NITROGEN, PHOSPHORUS, POTASSIUM, AND CALCIUM FERTILIZATION
}

\author{
Author: JONAS RUSCHEL \\ Adviser: Prof. Dr. QUIRINO AUGUSTO DE CAMARGO CARMELLO
}

\section{SUMMARY}

Two experiments were conducted with the objective to evaluate the effects of $\mathrm{N}, \mathrm{P}, \mathrm{K}$, and Ca fertilization on the production of citrus rootstock and nursery plants grown under screenhouse environment. The first study determined rates of $\mathrm{N}: \mathrm{P}: \mathrm{K}: \mathrm{Ca}$ to support optimal nutritional status of Rangpur lime rootstock (C. limonia Osbeck). The experiment was arranged in a fractional factorial design of the $(1 / 25) 5^{4}$ type, with a total of 25 treatments, distributed within 5 blocks. The Rangpur lime seedlings were transplanted when 10-cm height into 3.8 $\mathrm{dm}^{3}$ containers filled with a commercial compost of Pinus bark, vermiculite, and perlite. Treatments presented rates of (g per plant): $\mathrm{N}$ $(0.31,0.62,1.25,2.5$ and 5$), \mathrm{K}(0.4,0.62,1.25,2.5$ and 5), $\mathrm{P}(0.35,1.0$, 2.0, 3.0 and 4.0) and $\mathrm{Ca}(3.5,5.0,6.0,7.0$ and 8.0). Phosphorus and $\mathrm{Ca}$ rates were all applied to the compost before transplant of seedlings, while $\mathrm{N}$ and $\mathrm{K}$ rates were after split into 20 weekly applications via fertigation. Nutrients were applied as ammonium nitrate, triple 
superphosphate, potassium chloride, and gypsum. We concluded that better response of Rangpur lime rootstock was attained at $\mathrm{N}=3.5, \mathrm{P}=$ 2.7, $\mathrm{K}=2.0$ and $\mathrm{Ca}=6.5 \mathrm{~g}$ per plant. The second study determined rates of $\mathrm{N}: \mathrm{K}: \mathrm{Ca}$ to support optimal nutritional status of 'Pêra' sweet orange [C. sinensis (L.) Osbeck] nursery plants. The experiment was arranged in a fractional factorial design of the $(1 / 5) 5^{3}$ type, with a total of 25 treatments, also distributed within 5 blocks. Buds of 'Pêra' were grafted on 4-month-old 'Rangpur' lime seedlings grown in $3.8 \mathrm{dm}^{3}$ containers filled with compost. After bud take, the rootstock stem was cut off and treatments application were initiated Treatments presented rates of (g per plant): $\mathrm{N}(0.37,0.75,1.50,3.0$ and 6.0), $\mathrm{K}(0.37,0.75$, 1.50, 3.0 and 6.0) and $\mathrm{Ca}(0.6,1.8,3.0,4.2$ and 5.4). Phosphorus (2.7 g per plant) was applied before rootstock transplant. Rates of $\mathrm{N}, \mathrm{K}$, and $\mathrm{Ca}$ were split into 24 weekly applications via fertigation. Nutrients were applied as $\mathrm{NH}_{4} \mathrm{NO}_{3}, \mathrm{KCl}$ and $\mathrm{CaCl}_{2}$. Concentration of carbohydrates was not affected by fertilization. Our data suggest that optimum nutritional status of nursery plants are possible at fertilizer rates of $\mathrm{N}=5.0, \mathrm{~K}=2.0$ and $\mathrm{Ca}=5.0$ g per plant. 


\section{INTRODUÇÃO}

Atualmente a citricultura representa uma das mais importantes atividades agrícolas no Brasil, sendo que o país é um dos maiores produtores mundiais de suco cítrico concentrado e congelado.

Embora a citricultura ocupe lugar de destaque na agroindústria paulista e possua tecnologia avançada nos diversos segmentos de produção, a forma de propagação das plantas cítricas pouco evoluiu nas últimas décadas. São produzidas no planalto paulista, em média, 8 a 10 milhões de mudas cítricas (Mourão Filho et al., 1998).

Um dos maiores custos na instalação de um pomar cítrico é com as mudas e estas, só demonstram o seu potencial produtivo, entre 6 e 8 anos após o plantio.

Outro aspecto que deve ser considerado na instalação de um pomar, é a qualidade da muda cítrica, pois em 1998 milhões de árvores foram erradicadas devido à clorose variegada dos citros (CVC) e outras doenças. Boa parte dessas plantas, nem chegou a produzir, por uma razão simples: elas já foram para o campo com algum tipo de doença, ou seja, já saíram do viveiro contaminadas. Esse avanço da CVC tem comprometido a citricultura paulista. 
Com o objetivo de melhorar a qualidade sanitária das mudas cítricas utilizadas no Estado de São Paulo, a Secretaria de Agricultura e Abastecimento, instituiu o Programa de Certificação de Mudas de Citros, que prevê a utilização de um ambiente protegido, onde as mudas devam ser obtidas em vasos, com substrato e água desinfetados e materiais vegetais indexados para viroses e para a CVC (Carvalho, 1998).

Tendo em vista que o futuro da cultura depende do controle dessa doença, a produção de mudas sadias, através o Sistema de Certificação de Mudas, é o meio para se de garantir a sanidade inicial dos pomares.

A partir de 2003, a legislação irá proibir a comercialização de mudas produzidas em viveiros tradicionais em solo. Esse fato tem levado a maioria dos grandes produtores a iniciarem a produção de porta-enxertos em tubetes e a produção de mudas envasadas, ambas com substrato e em um ambiente protegido. Nesse sistema, a composição do substrato e o balanço nutricional adequado são de grande importância.

Um dos problemas enfrentados na produção de mudas cítricas no sistema de vasos é, o de se colocar à disposição das culturas, no periodo de maior exigência, a quantidade de nutrientes necessária para o seu desenvolvimento, diminuindo desse modo, o periodo de viveiro. Esse fato, faz com que sejam de extrema importância os estudos da nutrição mineral dos porta-enxertos e das mudas cítricas, para que se consiga dominar todas as etapas da produção de mudas certificadas, entre as quais pode-se citar: o conhecimento das necessidades nutricionais dos citros e a determinação da adubação balanceada, a qual visa uma nutrição adequada. 
Além de existirem alguns poucos trabalhos na literatura à respeito da adubação na fase de viveiro ainda não existe recomendação de adubação nas condições brasileiras, para a produção de mudas em vasos. Considerando-se a escassez de informações à respeito da nutrição e da produção de mudas de citros em vasos no Brasil, verificase a importância deste trabalho, que teve como objetivos:

a) Avaliar os efeitos da adubação N, P, K e Ca na produção de porta-enxertos de limoeiro 'Cravo';

b) Determinar a combinação de doses que proporciona uma enxertia mais precoce e a produção de mudas com o menor tempo de viveiro;

c) Avaliar os efeitos da adubação N, P, K e Ca sobre o balanço de carboidratos solúveis totais, a produção de material seco da parte aérea e das raízes, o volume radical, a área foliar e o crescimento da muda certificada de laranjeira 'Pêra' sobre o porta-enxerto de limoeiro 'Cravo';

d) Estabelecer as doses mais adequadas dos nutrientes, para a produção de porta-enxertos e de mudas de citros no sistema de vasos, em ambiente protegido; 


\section{REVISÃO DE LITERATURA}

\subsection{Consideraçōes gerais}

A fruticultura é uma das atividades agrícolas de grande relevância no mundo, destacando-se a citricultura, devido à adaptação ecológica das plantas cítricas a todos os continentes e ao seu consumo generalizado. As frutas citricas, que incluem as laranjas (64\%), tangerinas (17\%), limões e limas $(9 \%)$ e os grapefruits e pomelos $(5 \%)$, podem ser consumidas "in natura", na forma de suco, utilizadas em produtos de confeitaria, doces, compotas, vinho e vinagre de laranja. A casca fornece óleos essenciais e pectina. O bagaço, resíduo da extração do suco e do óleo da casca, é utilizado, principalmente, no preparo de ração animal e, das folhas, podem ser extraídos óleos essenciais utilizados na indústria de cosméticos (Passos, 1989; Koller, 1994; Neves \& Boteon, 1998).

O Brasil detém a liderança mundial na produção de laranjas. No ano de 2001 foram produzidos cerca de 18 milhões de toneladas de laranja, sendo exportados um total de 63.104 toneladas. Na região sudeste, destaca-se o estado de São Paulo, com $82 \%$ da produção brasileira. Em segundo lugar vem o Nordeste, com destaque para os estados de Sergipe e Bahia, e em terceiro lugar, a região Sul, sendo a área colhida nessas regiões de 668.654, 109.838 e 50.985 hectares, 
respectivamente (FNP, 2002). O Brasil possui uma participação superior a $80 \%$ no consumo internacional de suco de laranja concentrado congelado, sendo que o estado de São Paulo é responsável por 98\% da produção e da exportação brasileira de suco.

\subsection{Nitrogênio, fósforo, potássio e cálcio em citros}

O nitrogênio desempenha funções fisiológicas, estruturais e de osmorregulação na planta. Ele é absorvido pelas raizes das plantas na forma iônica, como íons nitrato e/ou amônio. A maior parte do nitrato é reduzida e incorporada em compostos orgânicos nas raizes. O nitrato é móvel no xilema, podendo ser armazenado nos vacúolos das células das raizes e, principalmente, na parte aérea. Possui papel fundamental no metabolismo vegetal, por ser constituinte de proteinas e ácidos nucléicos (Mengel \& Kirkby, 2001; Marschner, 1995).

O fósforo é componente de compostos orgânicos, tais como: ésteres de carboidratos, fosfolipídios, coenzimas e nucleoproteínas. Ele participa de funções críticas, na respiração, na fotossintese, no armazenamento e na transferência de energia, na divisão celular, no crescimento das células e em vários outros processos das plantas (Smith, 1966; Lopes, 1989). As plantas absorvem a maior parte do fósforo como ín ortofosfato primário $\left(\mathrm{H}_{2} \mathrm{PO}_{4}^{-}\right)$, sendo facilmente redistribuído pelo floema (Mengel \& Kirkby, 2001).

O potássio é absorvido pelas raizes na forma de $\mathrm{K}^{+}$, sendo esse processo essencialmente ativo. Ele desempenha várias funções na planta: o controle da turgidez do tecido, a ativação de muitas enzimas 
envolvidas na respiração e na fotossintese, a abertura e fechamento de estômatos, o transporte de carboidratos, a transpiração, a resistência à geada, à seca, à salinidade e à doença, a resistência ao acamamento e a manutenção da qualidade dos produtos (Malavolta, 1980; Mengel \& Kirkby, 2001; Marschner, 1995).

O cálcio pode ser encontrado no apoplasto, firmemente ligado às estruturas, imobilizado nas paredes celulares e na superfície externa da membrana plasmática. A função do cálcio como componente estrutural de macromoléculas, está relacionada à sua capacidade de coordenação, que produz ligações intermoleculares estáveis mas reversiveis, predominando na parede celular e na membrana plasmática. O cálcio também atua como um segundo mensageiro, na condução do sinal entre os fatores ambientais $\mathrm{e}$ as respostas da planta em termos de crescimento e desenvolvimento (Malavolta, 1980; Marschner, 1995).

Simão (1998) comenta que para citros, o desequilíbrio fisiológico pode ocorrer pela ausência de um ou mais elementos. A ausência de cálcio induz a planta a uma absorção elevada de nitrogênio, potássio e magnésio, apresentando sintoma de toxidez desses elementos, em vez de causar deficiência de cálcio.

Alguns trabalhos relatam efeitos benéficos da adubação fosfatada na fase inicial de crescimento de porta-enxertos cítricos (Rocha et al., 1994; Fonseca et al., 1994; Camargo et al., 1990; Bueno \& Souza, 1989). Além do fósforo, o nitrogênio também está muito relacionado com o desenvolvimento vegetativo, principalmente nas plantas novas, proporcionando o aumento no número e no tamanho das folhas, estimulando o crescimento vegetativo (Coelho \& Verlengia, 1973).

Em citros, a importância do fornecimento de cálcio foi relatada 
por Gallo et al. (1966) em laranja Baianinha, onde houve correlação linear entre o teor de cálcio na folha, fornecido através do superfosfato triplo, com a produção de frutos. Quaggio (1991) observou que os teores foliares de $\mathrm{Ca}, \mathrm{Mg}$ e $\mathrm{K}$ dependem, não somente dos teores desses nutrientes no solo, mas também das relações de equilíbrio entre eles, pois há um forte antagonismo entre $\mathrm{Ca}$ e $\mathrm{K}$ na nutrição da laranjeira e, por essa razão, a relação $\mathrm{Ca} / \mathrm{K}$ no solo é importante para se assegurar um bom suprimento de $\mathrm{Ca}$ e alta produtividade.

Respostas ao fósforo, ao nitrogênio e ao cálcio em porta-enxertos na fase inicial do crescimento têm sido observadas em diversos trabalhos realizados em sementeira, em casa-de-vegetação (Carvalho \& Souza, 1988; Bueno \& Souza, 1989; Camargo et al., 1990; Carvalho, 1994b).

\subsection{Produção de mudas de citros em vasos}

Para a citricultura, é fundamental a excelente qualidade das mudas, para que os acréscimos na produção sejam também uma conseqüência do aumento de produtividade (Porto, 1976). A qualidade das mudas cítricas é um dos fatores mais importantes na formação de um pomar, sendo de interesse, a obtenção de mudas sadias, vigorosas, de rápido crescimento e com um sistema radicular bem desenvolvido (Fortes, 1991).

O porta-enxerto pode ser considerado como a base da citricultura, pois dele depende a qualidade de uma boa muda. Para a obtenção de mudas qualidade elevada, o passo inicial é produzir porta- 
enxertos vigorosos e em curto espaço de tempo, proporcionando um retorno econômico mais rápido (Fortes, 1991).

A produção de mudas de citros no campo tem sido substituída pela produção em ambiente protegido (Carvalho, 1998). Esse sistema possibilita o controle de infecções causadas por patógenos; maior rapidez no desenvolvimento da muda, através de substratos preparados especialmente; o controle adequado da nutrição; a produção de mudas com um sistema radical bem desenvolvido, sem traumatismos e, conseqüentemente, facilidade no transplante; e a possibilidade de cultivo de um número de plantas dez vezes maior na mesma área (Bridges \& Youtsey, 1977; Castle \& Rouse, 1990).

No sistema de produção de mudas em recipientes na Flórida (EUA), os porta-enxertos são produzidos em tubetes ou em bandejas e as mudas são obtidas em recipientes (sacolas plásticas ou vasos). Nesse sistema, as plantas são transplantadas aos 4 meses para os vasos, e após 3 ou 4 meses são enxertadas, obtendo-se mudas de haste única, aproximadamente 12 meses após a semeadura (Castle \& Fergunson, 1982). Atualmente, esse sistema é o recomendado pela Secretaria de Agricultura e Abastecimento do Estado de São Paulo para a produção de mudas certificadas, livres da gomose e da CVC (Panzani et al., 1994).

$\mathrm{Na}$ formação da muda pode ocorrer a interrupção do surto de crescimento da borbulha, ocasionando o atraso na formação e o comprometimento da qualidade da muda (Araújo \& Souza, 1994). Quando mais de um surto de crescimento é necessário para a formação da muda, pode-se observar entrenós mais curtos, desvio na direção do crescimento ou diferença na cor e na textura da casca (Gama, 1983). A nutrição mineral inadequada é um dos fatores que podem ocasionar esse distúrbio (Leopold, 1984). 
Quando as mudas são produzidas em recipientes, o crescimento é influenciado pelo volume limitado e pela fertilidade do substrato, além de suas características fisicas. O volume de substrato limitado pode ser compensado pelo aumento nas doses de fertilizantes adicionadas. Maiores valores de altura, diâmetro e material seco total foram obtidos por Rezende et al. (1995), com o aumento das doses de fósforo. A complementação da fertilidade do substrato pode ser feita através de adubaçōes corretivas e de cobertura.

\subsection{Nutrição mineral e balanço de carboidratos}

A deficiência de nitrogênio provoca alteraçōes na distribuição de fotoassimilados e de nutrientes entre as raízes e a parte aérea, e o efeito mais freqüente é o aumento das quantidades de carboidratos na raízes levando a um aumento na relação raízes/parte aérea (Wilson, 1988; Rufty et al., 1990). A absorção do nitrogênio implica no consumo de esqueletos carbônicos para a incorporação do amônio formado, ocorrendo uma competição entre a sintese de sacarose e a de aminoácidos (Marschner, 1995).

Deficièncias severas de fósforo interferem no transporte de fotoassimilados das folhas, levando a um acúmulo de amido (Barker, 1979).

O potássio é um dos elementos que desempenha função ativa na formação do amido, dos açúcares e das partes lenhosas, estando relacionado com o endurecimento do lenho, tornando-o mais firme e vigoroso (Hume, 1952). O transporte de fotossintetados é inibido pela 
deficiência de potássio, ocorrendo uma interrupção na conversão dos produtos intermediários em sacarose e, um conseqüente acúmulo de carboidratos solúveis, inclusive açúcares redutores. (Natr, 1972; Huber, 1985).

O cálcio é o elemento formador da parede das células vegetais, e a sua deficiência nos tecidos das folhas de limão 'Rugoso' demonstrou que ocorre um acúmulo de amido e de açúcares solúveis (Lavon et al., 1995). Outro aspecto importante do cálcio é o retardamento na senescência das folhas (Poovaiah, 1988).

\subsection{Adubação das mudas de citros}

O principal objetivo de um programa de adubação em viveiros de citros é o crescimento máximo das mudas. Esse crescimento vigoroso é obtido através da aplicação de doses elevadas de fertilizantes (Castle \& Fergunson, 1982). Entretanto, os fundamentos dessa prática são empíricos, pois a adubação dos viveiros está baseada nos mesmos principios utilizados para as plantas adultas (Castle \& Rouse, 1990). As quantidades, fórmulas e freqüências utilizadas são baseadas na experiência individual dos produtores, não se sabendo, porém, se essa é a melhor prática ou a mais econômica. A nutrição mineral exerce uma grande influência em todas as fases da formação da muda cítrica e sendo assim, a fertilização após a enxertia também afeta o desenvolvimento final da muda (Graff et al., 1994).

Na Flórida, EUA, as doses de fertilizantes aplicados, via água de irrigação, correspondem a doses médias de 3,2; 0,55 e 1,8 g por planta 
de N, P e K, respectivamente (Castle \& Rouse, 1990).

Doses menores que $50 \mathrm{mg}$ de $\mathrm{N}$ por planta por semana foram insuficientes para se ter um crescimento ótimo das mudas cítricas. As doses que demonstraram os melhores resultados variaram de 120 a 140 mg por planta por semana (Maust \& Williamson, 1991). Na África do Sul utiliza-se fertirrigação com solução contendo $250 \mathrm{mg} \mathrm{L}^{-1}$ de N (Coetzee et al., 1993).

De acordo com Smith (1966), Chapman (1968) e Embleton et al. (1978) há vários relatos sobre as interações entre os nutrientes nas plantas citricas. Geralmente, as concentrações de $\mathrm{N}$ e de $\mathrm{K}$ estão inversamente relacionados, tendo o $\mathrm{N}$ um papel predominante sobre o do K. Estudos utilizando fatoriais de $\mathrm{N}$ e de $\mathrm{K}$, mostraram que as doses elevadas de $\mathrm{N}$ fornecidas resultaram em altas concentrações de $\mathrm{N}$ nas folhas e baixas de $\mathrm{K}$, enquanto que o aumento das doses de $\mathrm{K}$ resultaram no aumento das concentrações de $\mathrm{K}$ nas folhas e não interferiram nas concentrações de N (Reese \& Koo, 1975, Reitz \& Koo, 1960). Segundo Koo (1985), esses resultados indicam que o N é dominante na interação entre os dois nutrientes.

As concentrações de $\mathrm{P}$ nas folhas dependem do suprimento do nutriente, mas também da concentração de N. Suas concentrações nas folhas são inversamente relacionados, tendo o $\mathrm{N}$ um efeito pronunciado sobre o P (Reese \& Koo, 1975). Dessa forma, plantas com concentrações baixas ou deficientes em $\mathrm{N}$ podem apresentar concentrações altas de $\mathrm{P}$. Quando há excesso de $\mathrm{N}$ espera-se que hajam concentrações baixas de P. Assim, é praticamente impossivel encontrar folhas com altas concentrações de N e de P ao mesmo tempo (Smith, 1966).

Rezende et al. (1995) verificou que plantas de limoeiro 'Cravo', 
cultivadas em recipientes utilizando solo como substrato, responderam linearmente à aplicação de até $664 \mathrm{mg} \mathrm{kg}^{-1}$ de fósforo, para o diâmetro do caule e a altura das plantas.

O desenvolvimento do sistema radical nas plantas cítricas é estimulado pelo fósforo, principalmente na fase de crescimento inicial, sendo que os citros podem absorver nessa fase, cerca de $50 \%$ de todo o fósforo que é absorvido durante o ciclo da cultura (Black, 1967).

Diversos autores, investigando os efeitos da adubação fosfatada em porta-enxertos de limoeiro "Cravo", constataram efeitos benéficos na nutrição destes, até a fase de repicagem e no ponto de enxertia (Camargo et al., 1990; Lira, 1990; Paula, 1991; Fonseca et al., 1994).

Adubações fosfatadas provocam reduções nas concentrações de nitrogênio no material seco de plantas cítricas em crescimento (Souza, 1976) e em sementeira (Nicoli et al., 1986; Fontanezzi, 1989 e Fonseca et al., 1994). Este fato foi atribuído ao efeito de diluição ou à inibição competitiva entre os ânions fosfato e nitrato.

De acordo com Carvalho \& Souza (1987) e Fonseca et al. (1994) o aumento das doses de fósforo no substrato diminui as concentrações de potássio no material seco dos porta-enxertos. A justificativa dessa redução do potássio no material seco foi devido ao cálcio liberado pelo superfosfato simples, que reagiu antagonicamente com o potássio, diminuindo as concentrações destes no material seco, ou ainda devido ao efeito de diluição pelo crescimento maior das plantas.

Carvalho (1994b), trabalhando com a produção de plântulas de limoeiro 'Cravo' e tangerineira 'Sunki' em bandeja, obteve aumentos lineares para a altura das plantas, o diâmetro dos caules e a produção 
de material seco da parte aérea e das raizes, quando eram fornecidas soluções semanais de $\mathrm{KNO}_{3}$. Esse autor obteve respostas até a dose máxima aplicada de $3 \mathrm{~g} \mathrm{~L}^{-1}$ de $\mathrm{KNO}_{3}$ na água de irrigação. Em outro experimento semelhante, trabalhando com doses maiores, Carvalho \& Souza (1996) obtiveram respostas quadráticas, com o ponto de crescimento máximo das plantas na dose de $4,5 \mathrm{~g} \mathrm{~L} \mathrm{~L}^{-1}$, aplicados semanalmente para o limoeiro 'Cravo' e duas vezes por semana para a tangerina 'Cleópatra'.

O balanceamento entre $\mathrm{K}$, Ca e $\mathrm{Mg}$ é de fundamental importância para a nutrição das plantas e, principalmente, para os citros, devido à absorção preferencial do Ca. A concentração de Ca nas plantas citricas está relacionado diretamente com a quantidade fornecida pelo substrato (Smith, 1975). O desequilibrio nutricional entre $\mathrm{K} / \mathrm{Ca}$ provoca uma absorção radicular menor de $\mathrm{Ca}$, devido ao excesso de $\mathrm{K}$ (Jacobson et al., 1960), que causa uma produção menor em citros (Malavolta \& Violante Netto, 1989). 


\section{MATERIAL E MÉTODOS}

\subsection{Local de condução dos experimentos}

Foram realizados dois experimentos em viveiro telado do Centro Avançado de Tecnologia do Agronegócio de Citros "Sylvio Moreira", do Instituto Agronômico, em Cordeirópolis-SP. O viveiro atende às Normas para Produção de Mudas Certificadas de Citros da Coordenadoria de Assistência Técnica Integrada - CATI, apresentadas por Panzani et al. (1994) e suas caracteristicas foram descritas por Carvalho \& Laranjeira (1994). As áreas da sementeira e do viveiro possuem ante-sala e pedilúvio, são cobertas por plástico transparente e as laterais possuem telas antiafideo, impedindo a entrada de possiveis vetores da CVC. As bancadas para a produção de mudas são elevadas em $0,3 \mathrm{~m}$ do solo, facilitando o manejo e aumentando a proteção contra a contaminação por gomose, nematóides ou outras doenças de solo. A água utilizada na irrigação dos porta-enxertos e das mudas foi tratada com cloro. Em ambos os experimentos foi utilizado um substrato comercial rendimax, composto por casca de Pinus, vermiculita e perlita que apresentou as seguintes caracteristicas na análise química de rotina: P resina, 13,0 mg dm${ }^{-3}$; M.O., 731,7 $\mathrm{g} \mathrm{dm}^{-3}$; $\mathrm{pH} \mathrm{CaCl}_{2}, 5,2 ; \mathrm{K}=2,8$, $\mathrm{Ca}=18,8, \mathrm{Mg}=19,5, \mathrm{H}+\mathrm{Al}=27,5, \mathrm{SB}=27,5$ e CTC $=68,3 \mathrm{mmol}_{\mathrm{c}} \mathrm{dm}^{-3} ; \mathrm{V}=$ $60,2 \% ; \mathrm{Cu}=0,4, \mathrm{Fe}=13,6, \mathrm{Mn}=17,1$ e $\mathrm{Zn}=1,4 \mathrm{mg} \mathrm{dm}^{-3}$. 


\subsection{Delineamentos experimentais e tratamentos}

O primeiro experimento foi realizado utilizando-se um delineamento fatorial fracionado $(1 / 25) 5^{4}$, com quatro niveis de nutrientes $(\mathrm{N}, \mathrm{P}, \mathrm{K}$ e Ca) e cinco doses, num total de 25 tratamentos, repartidos em 5 blocos de 5 tratamentos (Conagin \& Jorge, 1982). Os tratamentos consistiram na combinação das doses totais, em g por planta: $N(0,31 ; 0,62 ; 1,25 ; 2,5$ e 5), $\mathrm{K}(0,4 ; 0,62 ; 1,25 ; 2,5$ e 5$), \mathrm{P}(0,35 ; 1,0 ; 2,0 ; 3,0$ e 4,0$)$ e Ca $(3,5 ; 5,0 ; 6,0$; $7,0$ e 8,0$)$, fornecidas durante o ciclo de desenvolvimento do porta-enxerto no telado. A descrição dos tratamentos é apresentada na Tabela 1, onde os números dos tratamentos indicam as doses de $\mathrm{N}, \mathrm{P}, \mathrm{K}$ e $\mathrm{Ca}$, respectivamente.

Tabela 1. Esquema de distribuição dos tratamentos nos blocos, indicando os niveis das doses de nitrogênio, fósforo, potássio e cálcio.

\begin{tabular}{ccccc}
\hline Bloco I & Bloco II & Bloco III & Bloco IV & Bloco V \\
\hline & Níveis de N, P, K e Ca dos tratamentos (1) & \\
1111 & 1342 & 1523 & 1254 & 1435 \\
2541 & 2222 & 2453 & 2134 & 2315 \\
3421 & 3152 & 3333 & 3514 & 3245 \\
4351 & 4532 & 4213 & 4444 & 4125 \\
5231 & 5412 & 5143 & 5324 & 5555 \\
\hline
\end{tabular}

(1) Niveis $1,2,3,4$ e 5 correspondem para cada nutriente, em $\mathrm{g}$ por planta, a: $\mathbf{N}(0,31 ; 0,62 ; 1,25$; $2,5$ e 5$), \mathrm{K}(0,4 ; 0,62 ; 1,25 ; 2,5$ e 5$)$, P $(0,35 ; 1,0 ; 2,0 ; 3,0$ e 4,0$)$ e Ca $(3,5 ; 5,0 ; 6,0 ; 7,0$ e 8,0$)$.

No segundo experimento, foi mantida fixa a dose de P, e utilizou-se um delineamento fatorial fracionado $(1 / 5) 5^{3}$, com três níveis de nutrientes $(\mathrm{N}, \mathrm{K}$ e $\mathrm{Ca})$ e cinco doses, num total com 25 tratamentos repartidos em 5 blocos de 5 tratamentos (Conagin \& Jorge, 1977). Os tratamentos e os blocos são apresentados na Tabela 2 , na qual os números indicam as doses de $\mathrm{N}, \mathrm{K}$ e $\mathrm{Ca}$, respectivamente. 
Tabela 2. Esquema da distribuição dos tratamentos nos blocos, indicando os niveis das doses de nitrogênio, potássio e cálcio.

\begin{tabular}{ccccc}
\hline Bloco I & Bloco II & Bloco III & Bloco IV & Bloco V \\
\hline & Niveis de & N, K e Ca dos tratamentos (1) & \\
\hline 111 & 134 & 152 & 125 & 143 \\
254 & 222 & 245 & 213 & 231 \\
342 & 315 & 333 & 351 & 324 \\
435 & 453 & 421 & 444 & 412 \\
523 & 541 & 514 & 532 & 555 \\
\hline
\end{tabular}

(1) Niveis $1,2,3$ e 4 correspondem para cada nutriente, em $\mathrm{g}$ por planta, a: $\mathbf{N}(0,37 ; 0,75 ; 1,50 ; 3,0$ e 6,0$), \mathrm{K}(0,37 ; 0,75 ; 1,50 ; 3,0$ e 6,0$)$ e Ca $(0,6 ; 1,8 ; 3,0 ; 4,2$ e 5,4$)$.

O primeiro experimento foi conduzido até a fase de enxertia do porta-enxerto limoeiro 'Cravo' (Citrus limonia, Osbeck). As doses totais de P e o Ca foram fornecidos via pré-enriquecimento do substrato, na forma de superfosfato triplo e de gesso agrícola. $\mathrm{O} \mathrm{N}$ e $\mathrm{o} \mathrm{K}$ foram fornecidos semanalmente via fertirrigação após o transplante, utilizando-se o nitrato de amônio e o cloreto de potássio como fontes, divididos em 20 aplicações semanais.

O segundo experimento recebeu as doses de $\mathrm{N}, \mathrm{P}, \mathrm{K}$ e $\mathrm{Ca}$ determinadas no primeiro experimento até o ponto comercial de enxertia $(\mathrm{N}=3,5 ; \mathrm{P}=2,7 ; \mathrm{K}=2,0$ e $\mathrm{Ca}=6,5 \mathrm{~g}$ por planta). As doses totais de $\mathrm{P}$ e o Ca foram fornecidos via pré-enriquecimento do substrato, na forma de superfosfato triplo e de gesso agrícola. O $\mathrm{N}$ e o $\mathrm{K}$ foram fornecidos semanalmente via fertirrigação após o transplante, utilizando-se nitrato de amônio e o cloreto de potássio como fontes. Após o pegamento da enxertia ("T" invertido), foi realizada a decapitação do porta-enxerto e iniciou-se a aplicação dos tratamentos referentes ao segundo experimento. Os nutrientes $\mathrm{N}, \mathrm{K}$ e o Ca foram fornecidos via fertirrigação, divididos em 24 aplicações semanais. As fontes utilizadas para os tratamentos foram $\mathrm{NH}_{4} \mathrm{NO}_{3}, \mathrm{KCl}$ e Ca Cl 2 . 
Os micronutrientes foram fornecidos via foliar, através de pulverizações de solução preparada com sais solúveis com Mn, Zn e B, nas dosagens recomendadas por GPACC (1994). O Cu foi fornecido por meio das aplicações preventivas do tratamento fitossanitário.

\subsection{Instalação e condução}

Os porta-enxertos de limoeiro 'Cravo' foram produzidos no Centro Avançado de Tecnologia do Agronegócio de Citros "Sylvio Moreira" em tubetes de $50 \mathrm{~cm}^{3}$ e transplantados quando atingiram $10 \mathrm{~cm}$ de altura, para vasos $\left(3,8 \mathrm{dm}^{3}\right)$ contendo substrato comercial rendimax, quando iniciou-se a aplicação dos tratamentos. As plantas do primeiro experimento foram conduzidas de acordo com Carvalho (1998) e coletado quando estavam aptas para serem enxertadas, após 5 meses de cultivo (20 semanas).

O segundo experimento foi conduzido de maneira similar ao primeiro até as plantas atingirem o ponto de enxertia. Esta foi realizada pelo método do "T" invertido, com borbulhas de laranjeira 'Pêra IAC 2000' (Citrus sinensis, L. Osbeck) provenientes de borbulheira livre de viroses e CVC, mantida no Centro Avançado de Tecnologia do Agronegócio de Citros "Sylvio Moreira". Após a verificação do pegamento do enxerto, realizou-se o forçamento da brotação através da decapitação do porta-enxerto. As plantas receberam os tratamentos e foram conduzidas até o ponto de muda, com haste única, 6 meses após a enxertia.

\subsection{Avaliações}

Nos experimentos avaliou-se as produções de material seco das 
folhas, caule, raizes e do total da planta (g por planta), altura das plantas $(\mathrm{cm})$, diâmetro do caule $(\mathrm{mm})$, volume de raízes $\left(\mathrm{cm}^{3}\right)$, área foliar $\left(\mathrm{cm}^{2}\right)$, concentração total de nutrientes nas folhas (folhas maduras totalmente expandidas) e, acúmulo dos nutrientes.

A parte aérea (folhas + haste principal) das plantas foi separada das raizes, lavadas sucessivamente com solução diluída de água e detergente, água, solução $\mathrm{HCl}$ e por último água deionizada. O material coletado foi seco em estufa a $65^{\circ} \mathrm{C}$ por $48 \mathrm{~h}$, pesado e moído $(<1,0 \mathrm{~mm})$.

As análises químicas para a determinação das concentrações totais de nutrientes presentes no material seco foram efetuadas após digestão sulfúrica e nítrico-perclórica. A digestão sulfúrica foi utilizada na obtenção do extrato para a determinação do nitrogênio pelo método semi-Kjeldhal. A digestão nítrico-perclórica foi utilizada na obtenção dos extratos para as determinações de P, K, Ca, Mg e S (Sarruge \& Haag, 1974). O P foi determinado por colorimetria de vanadato-molibdato, o $\mathrm{K}$ por fotometria de chama, o Ca e o Mg por espectrofotometria de absorção atômica e o S por turbidimetria. A partir das análises químicas, foram obtidos as concentrações totais de $\mathrm{N}, \mathrm{P}, \mathrm{K}, \mathrm{Ca}, \mathrm{Mg}$ e S $\left(\mathrm{g} \mathrm{kg}^{-1}\right)$.

Foi realizada a determinação dos carboidratos solúveis totais nas folhas, utilizando-se o método de Smith (1969), que foi descrito por Silva (1981). Esse método é baseado na digestão ácida das amostras com ácido sulfúrico e a precipitação dos carboidratos solúveis totais por sulfato de cobre.

\subsection{Análises estatísticas}

As análises de variância foram realizadas para todas as variáveis estudas, em função das doses dos nutrientes. Quando houve efeito 
significativo das doses, foram realizados ajustes de regressão polinomial. Para o primeiro experimento, foram ajustadas funções de resposta do tipo $\mathrm{Y}=\gamma_{0}+\gamma_{1} \mathrm{~N}+\gamma_{2} \mathrm{~N}^{2}+\gamma_{3} \mathrm{P}+\gamma_{4} \mathrm{P}^{2}+\gamma_{5} \mathrm{~K}+\gamma_{6} \mathrm{~K}^{2}+\gamma_{7} \mathrm{Ca}+\gamma_{8} \mathrm{Ca}^{2}+\gamma_{9} \mathrm{NP}+\gamma_{10} \mathrm{NK}+$ $\gamma_{11} \mathrm{NCa}+\gamma_{12} \mathrm{PK}+\gamma_{13} \mathrm{PCa}+\gamma_{14} \mathrm{KCa}$, onde $\mathrm{Y}$ é a variável dependente, $\gamma$ são os coeficientes de regressão e N, P, K e Ca as doses utilizadas dos nutrientes. No segundo experimento, foram ajustadas funções de resposta do tipo $\mathrm{Y}=$ $\gamma_{0}+\gamma_{1} \mathrm{~N}+\gamma_{2} \mathrm{~N}^{2}+\gamma_{3} \mathrm{~K}+\gamma_{4} \mathrm{~K}^{2}+\gamma_{5} \mathrm{Ca}+\gamma_{6} \mathrm{Ca}^{2}+\gamma_{7} \mathrm{NK}+\gamma_{8} \mathrm{NCa}+\gamma_{9} \mathrm{KCa}$, onde $\mathrm{Y}$ é a variável dependente, $\gamma$ são os coeficientes de regressão e $\mathrm{N}, \mathrm{K}$ e $\mathrm{Ca}$ as doses utilizadas dos nutrientes. As análises estatisticas foram realizadas utilizando-se o modo GLM do programa estatístico SAS (SAS Institute, 1996). Quando houve resposta significativa para apenas 1 ou 2 nutrientes, as funções foram simplificadas, considerando-se os niveis menores dos demais nutrientes (Apếndices 1, 2 e 3). Determinou-se as doses dos nutrientes que proporcionaram os valores maiores de produção de material seco (MS), volume de raízes, área foliar, diâmetro de caule, altura da planta, concentração e acúmulo dos nutrientes nos tecidos, através do cálculo diferencial $\mathrm{dx} / \mathrm{dy}=0$. 


\section{RESULTADOS E DISCUSSÃO}

\subsection{Produção de material seco}

$\mathrm{Na}$ produção de material seco (MS) das folhas e total do portaenxerto limoeiro 'Cravo' aos 5 meses após o transplante, houve interação entre $\mathrm{N}$ e Ca (Figura 1A e Figura 1D). As produções máximas de MS das folhas $(8,46 \mathrm{~g}$ por planta) e total $(23,15 \mathrm{~g}$ por planta) foram obtidas com as doses de $\mathrm{N}$ e de Ca: 5,00 e 6,04 e de 3,41 e 6,27 g por planta, respectivamente. Bernardi (1999) obteve incrementos maiores de MS do limoeiro 'Cravo', com doses inferiores de $\mathrm{N}$, aos 4 meses após o transplante. Entretanto, esse autor obteve interação entre doses de $\mathrm{N}$ e de $\mathrm{K}$ para a produção de MS.

Os incrementos da produção de MS em função do aumento das doses de $\mathrm{N}$ eram esperados uma vez que esse nutriente é constituinte de todas as proteínas, atuando diretamente sobre o crescimento e o metabolismo vegetal (Maust \& Williamson, 1994). O aumento da produção de $\mathrm{MS}$, com as doses de $\mathrm{Ca}$, pode ser explicado devido ao $\mathrm{Ca}$ ser constituinte da parede celular das células (Smith, 1975).

Houve interação entre $\mathrm{K}$ e $\mathrm{Ca}$ na produção de $\mathrm{MS}$ do caule (Figura 1B), com produção máxima de 7,2 g por planta nas doses de $\mathrm{Ca}$ de $5,26 \mathrm{~g}$ por planta e com as menores doses de $\mathrm{K}$. 
A

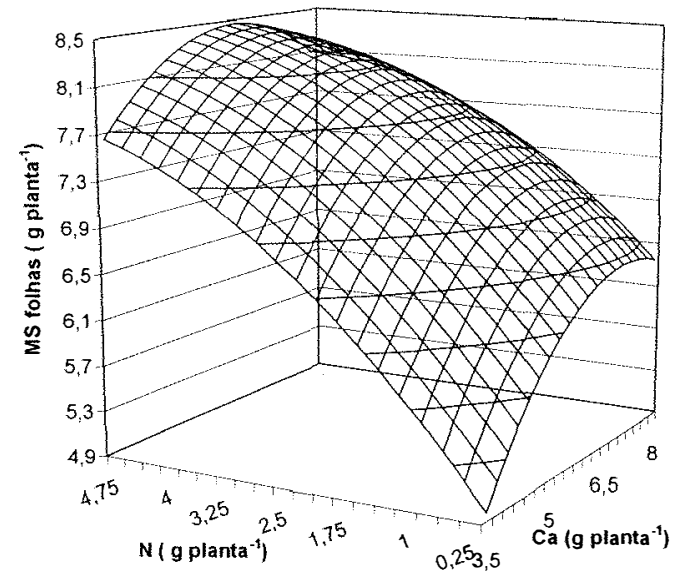

$\mathrm{Y}=-0,072 \mathrm{~N}^{2}+1,098 \mathrm{~N}-0,114 \mathrm{Ca}^{2}+1,637 \mathrm{Ca}-0,044 \mathrm{CaN}+0,406$ $\mathrm{R}^{2}=0,68$

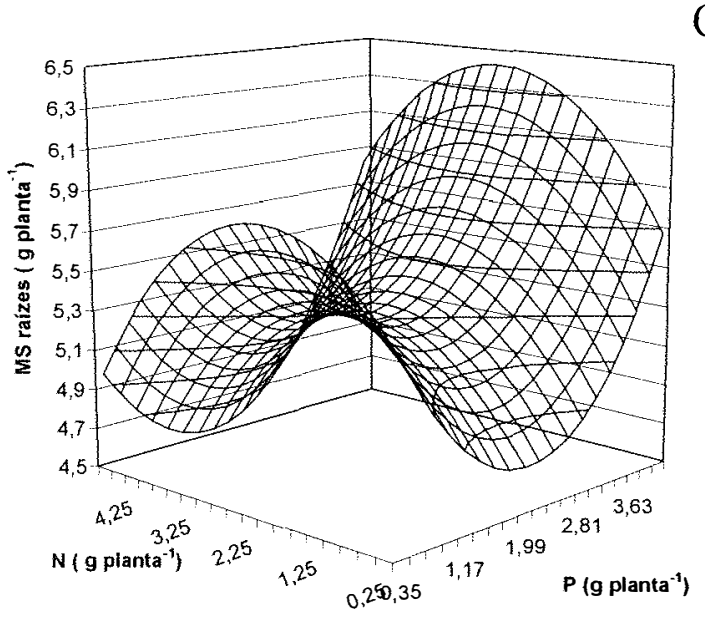

$\mathrm{Y}=-0,12 \mathrm{~N}^{2}+0,527 \mathrm{~N}+0,2393 \mathrm{P}^{2}-0,9834 \mathrm{P}+0,0329 \mathrm{PN}+5,5888$ $\mathrm{R}^{2}=0,68$
C

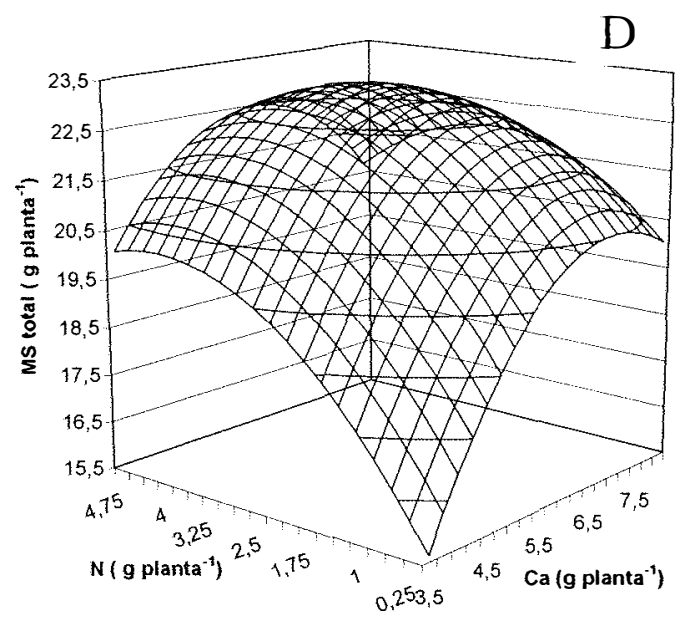

$\mathrm{Y}=-0,28 \mathrm{~N}^{2}+3,019 \mathrm{~N}-0,414 \mathrm{Ca}^{2}+5,797 \mathrm{Ca}-0,177 \mathrm{CaN}-0,189$ $R^{2}=0,62$

Figura 1- Produção de material seco do limoeiro 'Cravo' aos 5 meses após o transplante: folhas (A), caule (B), raizes (C) e total (D).

As doses mais altas de $\mathrm{K}$ interferiram negativamente na produção de MS do caule, possivelmente devido ao desequilíbrio entre K/Ca (Anderson, 1987). 
Bernardi (1999), estudando doses de NPK, obteve resposta crescente na produção de MS do caule para $\mathrm{K}$, até a dose de 2,67 g por planta.

Analisando-se a produção de MS das raizes (Figura 1C), observase a interação entre $\mathrm{N}$ e $\mathrm{P}$, na qual doses acima de 2,44 g de $\mathrm{N}$ por planta causaram redução no $\mathrm{MS}$ das raízes. Doses altas de $\mathrm{N}$ diminuíram o desenvolvimento do sistema radical (Ford et al., 1957; Smith, 1965). Observou-se uma redução no MS até a dose de 1,78 g de P por planta e um aumento acima desta.

Os resultados da produção de material seco (MS) das folhas das mudas de laranjeira 'Pêra' aos 6 meses após a enxertia ajustaram-se ao modelo quadrático $(\mathrm{P}<0,05)$ em função das doses de $\mathrm{K}$ (Tabela 3). A produção máxima foi de $16,91 \mathrm{~g}$ por planta obtida com a dose de 4,25 g por planta de K. Bernardi et al. (2000a) encontrou resposta quadrática ao fornecimento de $\mathrm{N}$, obtendo menor MS das folhas.

Para as produções de material seco total da parte aérea (MS PA), caule e MS total da planta houve interação entre N e K (Figuras 2B, 2C e 2D). Observou-se uma tendência linear muito intensa entre as doses de $\mathrm{N}$ e as produções de MS total, PA e caule na doses mais baixa de K. Essa mesmas interações entre $\mathrm{N}$ e K com a produção de MS total e da PA foram também verificadas por Bernardi et al. (2000a) em mudas de laranjeira 'Valência'/'Cravo'.

A produção máxima de MS total $(52,54 \mathrm{~g})$ foi obtida com as doses 6,0 e 1,0 g por planta de $\mathrm{N}$ e de $\mathrm{K}$, respectivamente. A interação entre $\mathrm{N}$ e $\mathrm{K}$ causou um efeito negativo do $\mathrm{K}$ a partir da dose de 1,0 g por planta de $\mathrm{K}$ quando causaram uma redução na produção total de MS (Figura 2B). A produção máxima de MS da PA foi de $37,97 \mathrm{~g}$, obtida com as doses $6,0 \mathrm{~g}$ de $\mathrm{N}$ e $1,25 \mathrm{~g}$ de $\mathrm{K}$ por planta. A produção máxima do caule 
foi de 10,53 g, com as doses 6,0 e 0,6 g por planta de $\mathrm{N}$ e $\mathrm{K}$, respectivamente (Figuras $2 \mathrm{~B}$ e $2 \mathrm{C}$ ).

Tabela 3. Função de resposta das variáveis matéria seca das folhas, MS da parte aérea, MS total da planta, MS do caule, MS das raízes, volume de raízes, área foliar, diâmetro do caule e altura das plantas, ajustadas para termos significativos obtidos para o limoeiro 'Cravo' e para as mudas de laranja 'Pêra'. As condições indicam os niveis dos nutrientes não significativos para os quais as equações foram ajustadas.

\begin{tabular}{|c|c|c|c|}
\hline Variável & Equação & Condição (g) & $\mathbf{R}^{2}$ \\
\hline \multicolumn{4}{|l|}{ Limoeiro } \\
\hline MS folhas & $\mathrm{Y}=-0,0722 \mathrm{~N}^{2}+1,0987 \mathrm{~N}-1,1144 \mathrm{Ca}^{2}+1,6367 \mathrm{Ca}-0,0444 \mathrm{CaN}+0,406$ & $\mathrm{P}=0,35$ e $\mathrm{K}=0,4$ & 0,68 \\
\hline MS caule & $\mathrm{Y}=0,0218 \mathrm{~K}^{2}+0,4977 \mathrm{~K}-0,2124 \mathrm{Ca}^{2}+2,922 \mathrm{Ca}-0,1362 \mathrm{CaK}-2,6284$ & $\mathrm{~N}=0,06$ e $\mathrm{P}=0,35$ & 0,64 \\
\hline MS raízes & $\mathrm{Y}=-\mathbf{0}, 12 \mathrm{~N}^{2}+0,527 \mathrm{~N}+0,2393 \mathrm{P}^{2}-0,9834 \mathrm{P}+0,0329 \mathrm{PN}+5,5888$ & $\mathrm{~K}=0,4$ e $\mathrm{Ca}=3,5$ & 0,68 \\
\hline MS PA & $\mathrm{Y}=-0,16 \mathrm{~N}^{2}+2,2278 \mathrm{~N}-0,3268 \mathrm{Ca}^{2}+4,509 \mathrm{Ca}-0,104 \mathrm{CaN}-2,0947$ & $\mathrm{~K}=0,4 \mathrm{e} \mathrm{Ca}=3,5$ & 0,66 \\
\hline MS total & $\mathrm{Y}=-0,28 \mathrm{~N}^{2}+3,0186 \mathrm{~N}-0,4141 \mathrm{Ca}^{2}+5,7974 \mathrm{Ca}-0,177 \mathrm{CaN}-0,1893$ & $\mathrm{~K}=0,4 \mathrm{e} \mathrm{Ca}=3,5$ & 0,62 \\
\hline $\begin{array}{l}\text { Altura de } \\
\text { planta }\end{array}$ & $Y=-0,8564 \mathrm{Ca}^{2}+12,6916 \mathrm{Ca}+39,997$ & $\begin{array}{l}\mathrm{P}=0,35, \mathrm{~K}=0,4 \text { e N=} \\
0,06\end{array}$ & 0,54 \\
\hline $\begin{array}{l}\text { Diâmetro de } \\
\text { caule }\end{array}$ & $\mathrm{Y}=-0,0574 \mathrm{Ca}^{2}+0,7504 \mathrm{Ca}+3,7459$ & $\begin{array}{l}\mathrm{P}=0,35, \mathrm{~K}=0,4 \mathrm{eN}= \\
0,06\end{array}$ & 0,25 \\
\hline \multicolumn{4}{|l|}{ Laranjeira } \\
\hline MS Folhas & $\mathrm{Y}=-0,34 \mathrm{~K}^{2}+2,947 \mathrm{~K}+10,53$ & $\mathrm{Ca}=0,6 \mathrm{e} \mathrm{N}=0,37$ & 0,69 \\
\hline MS PA & $\mathrm{Y}=0,276 \mathrm{~N}^{2}+1,28 \mathrm{~N}-0,59 \mathrm{~K}^{2}+5,447 \mathrm{~K}-0,65 \mathrm{KN}+19,342$ & $\mathrm{Ca}=0,6$ & 0,69 \\
\hline MS total & $\mathrm{Y}=0,483 \mathrm{~N}^{2}+0,961 \mathrm{~N}-0,753 \mathrm{~K}^{2}+7,133 \mathrm{~K}-0,955 \mathrm{KN}+28,776$ & $\mathrm{Ca}=0,6$ & 0,68 \\
\hline MS caule & $\mathrm{Y}=0,101 \mathrm{~N}^{2}+0,371 \mathrm{~N}-0,141 \mathrm{~K}^{2}+1,486 \mathrm{~K}-0,219 \mathrm{KN}+4,623$ & $\mathrm{Ca}=0,6$ & 0,67 \\
\hline MS raizes & $\mathrm{Y}=0,207 \mathrm{~N}^{2}-0,32 \mathrm{~N}-0,162 \mathrm{~K}^{2}+1,683 \mathrm{~K}-0,304 \mathrm{KN}+9,436$ & $\mathrm{Ca}=0,6$ & 0,63 \\
\hline Vol Raizes & $\mathrm{Y}=0,92 \mathrm{~N}^{2}-3,151 \mathrm{~N}-0,68 \mathrm{~K}^{2}+7,08 \mathrm{~K}-1,114 \mathrm{KN}+42,214$ & $\mathrm{Ca}=0,6$ & 0,52 \\
\hline Área foliar & $\mathrm{Y}=22,01 \mathrm{~N}^{2}+1,059 \mathrm{~N}-42,74 \mathrm{~K}^{2}+354,882 \mathrm{~K}-40,34 \mathrm{KN}+1266,959$ & $\mathrm{Ca}=0,6(\mathrm{P}<0,1)$ & 0,57 \\
\hline $\begin{array}{l}\text { Diâmetro de } \\
\text { caule }\end{array}$ & $\mathrm{Y}=0,034 \mathrm{~N}^{2}+0,03 \mathrm{~N}-0,029 \mathrm{~K}^{2}+0,416 \mathrm{~K}-0,064 \mathrm{KN}+7,045$ & $\mathrm{Ca}=0,6$ & 0,55 \\
\hline $\begin{array}{l}\text { Altura de } \\
\text { planta }\end{array}$ & $\mathrm{Y}=0,734 \mathrm{~N}^{2}+0,149 \mathrm{~N}-0,57 \mathrm{~K}^{2}+6,696 \mathrm{~K}-1,06 \mathrm{KN}+47,708$ & $\mathrm{Ca}=0,6$ & 0,67 \\
\hline
\end{tabular}



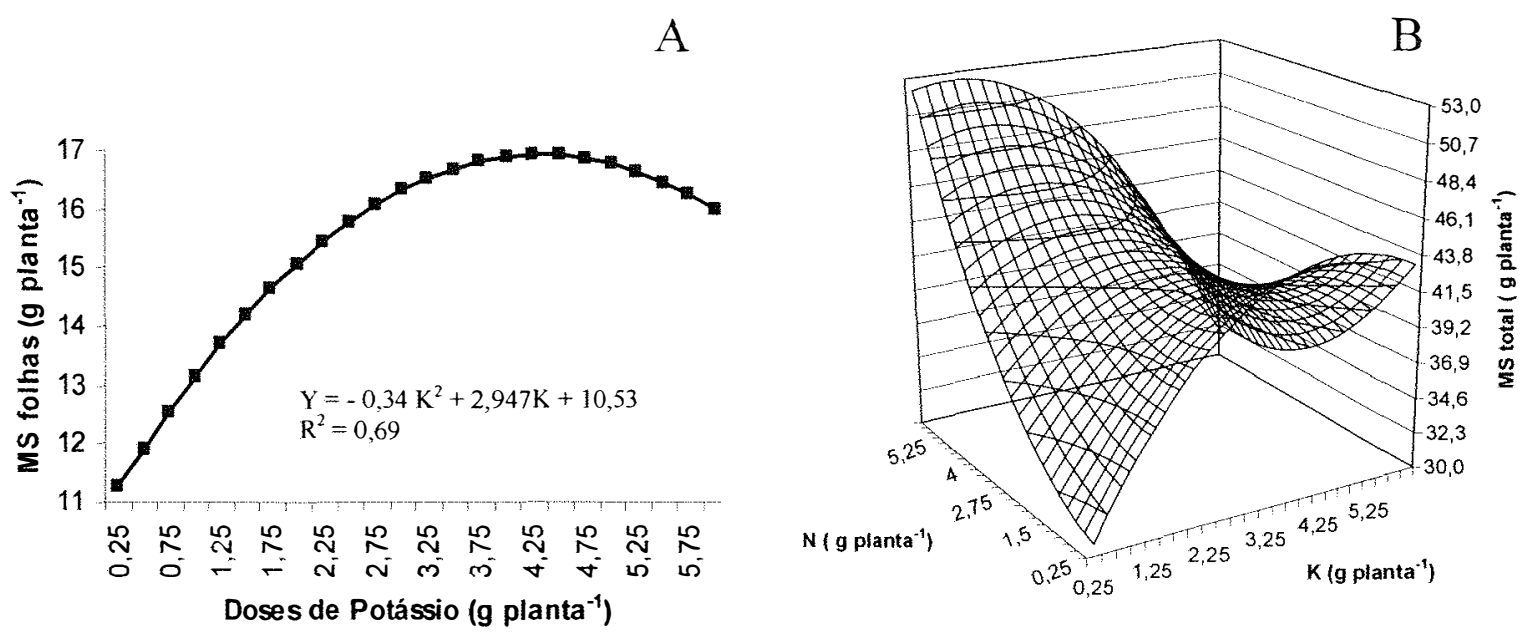

$\mathrm{Y}=0,483 \mathrm{~N}^{2}+0,961 \mathrm{~N}-0,753 \mathrm{~K}^{2}+7,133 \mathrm{~K}-0,955 \mathrm{KN}+28,776$ $\mathrm{R}^{2}=0,68$

$\mathrm{C}$
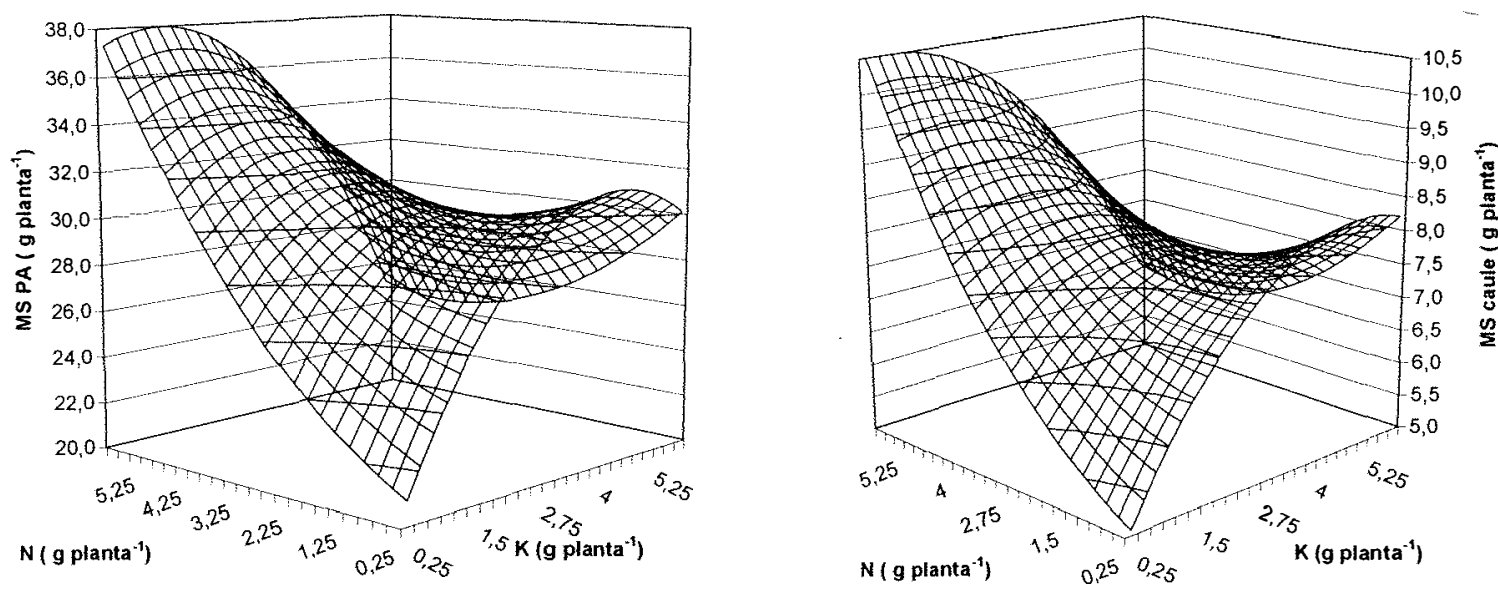

$Y=0,276 N^{2}+1,28 \mathrm{~N}-0,59 \mathrm{~K}^{2}+5,447 \mathrm{~K}-0,65 \mathrm{KN}+19,342$
$\mathrm{R}^{2}=0,69$

$\mathrm{Y}=0,101 \mathrm{~N}^{2}+0,371 \mathrm{~N}-0,141 \mathrm{~K}^{2}+1,486 \mathrm{~K}-0,219 \mathrm{KN}+4,623$ $R^{2}=0,67$

Figura 2 - Produção de material seco das mudas de laranjeira 'Pêra' aos 6 meses após a enxertia: folhas (A), total da planta (B), parte aérea (C) e caule (D). 


\subsection{Altura das plantas, diâmetro do caule, concentração de carboidratos solúveis totais, volume das raizes e área foliar}

Os resultados de altura das plantas do limoeiro 'Cravo' aos 5 meses após o transplante demostraram um efeito quadrático em função das doses de Ca (Figura 3A). A altura máxima foi de $87,02 \mathrm{~cm}$, com a dose 7,41 g de Ca por planta. Estes resultados concordam com os de Cipolli (1986), que obteve incrementos em altura devido às doses de Ca, em plantas conduzidas em viveiro no campo, um ano após o plantio.

$\mathrm{Na}$ altura das mudas de laranjeira 'Pêra' aos 6 meses após a enxertia as doses que variaram entre 5,25 e 6,0 g por planta de $\mathrm{N}$ e entre 0,25 e 2,25 g por planta de $\mathrm{K}$ apresentaram sempre alturas maiores que $68 \mathrm{~cm}$. A altura máxima foi de $75,07 \mathrm{~cm}$ com as doses de 6,0 e 0,25 g por planta de $\mathrm{N}$ e K, respectivamente (Figura 3B). Esses resultados são maiores que os encontrados por Bernardi et al. (2000a), que obtiveram altura máxima de $52,6 \mathrm{~cm}$ com as doses de $1,25 \mathrm{~g}$ por planta de $\mathrm{N}$ e $2,99 \mathrm{~g}$ por planta de $\mathrm{P}$. 

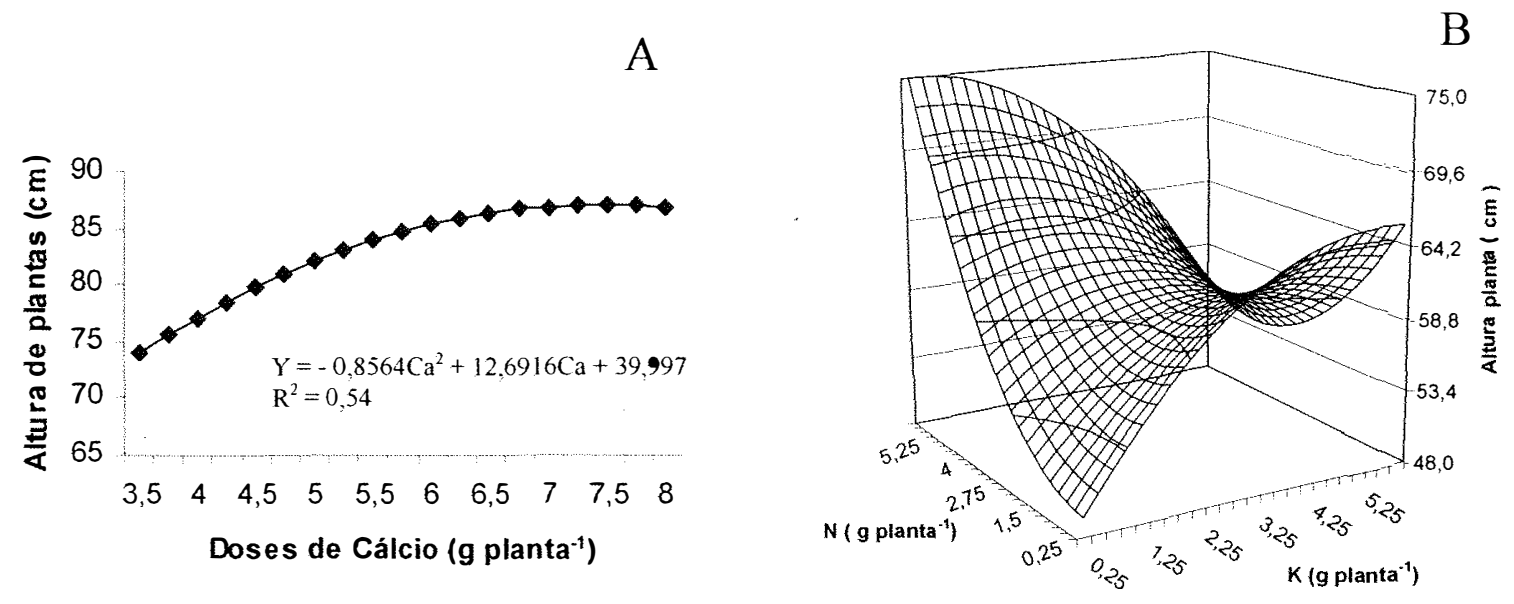
$Y=0,734 N^{2}+0,149 N-0,57 K^{2}+6,696 \mathrm{~K}-1,06 \mathrm{KN}+47,708$
$R^{2}=0,67$

Figura 3 - Altura das plantas de limoeiro 'Cravo' (A) aos 5 meses após o transplante e das mudas de laranjeira 'Pêra' (B) aos 6 meses após a enxertia.

O diâmetro do caule é uma característica morfológica importante para o porta-enxerto, pois é indicativo do momento da enxertia. No caso de muda tipo "pavio", o mercado tem preferência por mudas com diâmetros maiores.

O diâmetro do caule do porta-enxerto limoeiro 'Cravo' aos 5 meses após o transplante apresentou uma tendência quadrática em função das doses de $\mathrm{Ca}$, atingindo um diâmetro máximo de $6,54 \mathrm{~mm}$ com a dose de 6,54 g por planta de Ca (Figura 4A). Para a muda de laranjeira 'Pêra' aos 6 meses após a enxertia ocorreu uma interação entre $\mathrm{K}$ e $\mathrm{N}$, demonstrando aumentos em função da doses de $\mathrm{N}$ quando a dose de $\mathrm{K}$ era minima. O mesmo efeito pode ser verificado com doses de $\mathrm{K}$ e a dose mínima de $\mathrm{N}$. O maior diâmetro $(8,46 \mathrm{~mm})$ foi obtido com a dose mínima de $\mathrm{K}(0,25 \mathrm{~g}$ por planta) e a máxima de $\mathrm{N}$ (6,0 g por 
planta), entretanto, as doses medianas $(2,75$ a 6,0 e 2,75 a 4,5 g por planta de $\mathrm{N}$ e $\mathrm{K}$, respectivamente) apresentaram diâmetros que variaram de 7,84 a $8,32 \mathrm{~mm}$ (região mediana do gráfico). Portanto, dentro dos limites de 0,25 a 6,0 g por planta de $\mathrm{N}$ e 0,25 a 4,5 g por planta de $\mathrm{K}$, sempre houve incrementos de diâmetro, lembrando que a maior diferença no diâmetro entre a área do gráfico citada $(7,84 \mathrm{~mm})$ e o diâmetro máximo $(8,46 \mathrm{~mm})$ é de apenas 0,62 mm (Figura 4B).

Aumentos no diâmetro do caule, proporcionados pela adição de $200 \mathrm{mg} \mathrm{L}^{-1}$ de Ca em solução nutritiva, foram encontrados por Grassi Filho (1991) em porta-enxertos de limoeiro 'Cravo'. Já Bernardi (1999) obteve resposta quadrática em função das doses de $\mathrm{K}$ (até 2,67 g por planta) para esse parâmetro em limoeiro ‘Cravo'.

As quantidades de carboidratos solúveis totais nas folhas do limoeiro 'Cravo' aos 5 meses após o transplante e da laranjeira 'Pêra' aos 6 meses após a enxertia não tiveram efeito significativo $(\mathrm{P}<0,05)$ em função dos tratamentos. Isto contraria os resultados de Lavon et al. (1995), que encontraram acúmulos maiores de amido e de carboidratos solúveis totais, quando as plantas de citros estavam com concentraçōes baixas de Ca, e de Barker (1979), que encontrou acúmulo de amido em plantas com concentraçōes baixas de P e, os resultados de Natr (1972) e de Huber (1985), que encontraram acúmulos de carboidratos solúveis, quando existia deficiência de $\mathrm{K}$. Isso pode ser explicado pela concentraçōes altas de $\mathrm{K}$ encontradas nas folhas. 
A
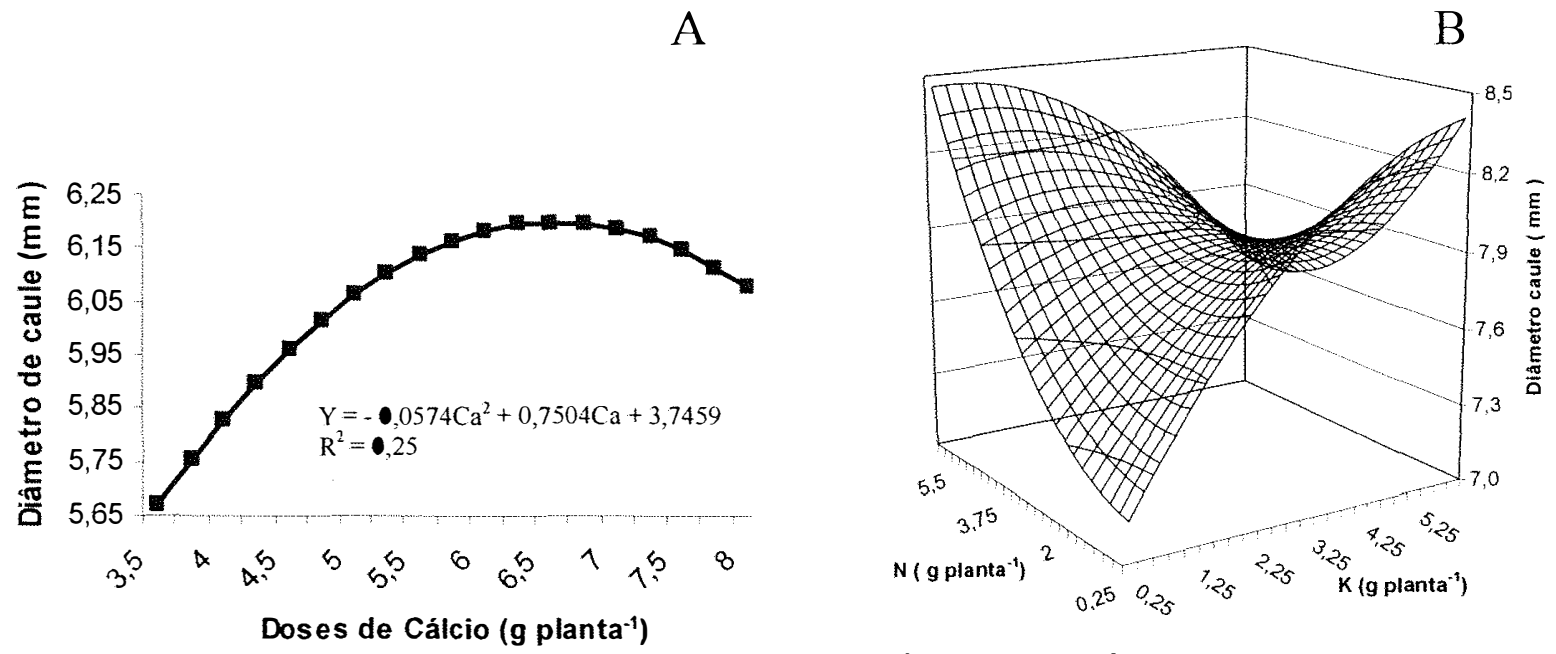

$\mathrm{Y}=0,034 \mathrm{~N}^{2}+0,03 \mathrm{~N}-0,029 \mathrm{~K}^{2}+0,416 \mathrm{~K}-0.064 \mathrm{KN}+7,045$ $\mathrm{R}^{2}=0,61$

Figura 4 - Diâmetro de caule do limoeiro 'Cravo' aos 5 meses após o transplante a $10 \mathrm{~cm}$ do colo da planta (A) e da laranjeira 'Pêra' aos 6 meses após a enxertia, $1 \mathrm{~cm}$ acima da enxertia (B).

No volume radical da laranjeira 'Pêra' aos 6 meses após a enxertia, houve interação entre $\mathrm{N}$ e $\mathrm{K}$, e os maiores volumes radicais foram obtidos com a maior dose de $\mathrm{K}$ e na menor de $\mathrm{N}$ e, na maior de $\mathrm{N}$ e na menor de $\mathrm{K}$ (Figura 5A). Isto pode ser explicado pelo fato das doses altas, tanto de $\mathrm{K}^{+}$como de $\mathrm{NH}_{4}{ }^{+}$, apresentarem inibição competitiva (Marschner, 1995). Segundo Ford et al. (1957) e Smith (1965), as raízes poderiam estar fornecendo os nutrientes necessários para o desenvolvimento da parte aérea de modo adequado, mesmo estando em quantidade pequena, justificando assim, o efeito negativo das doses de $\mathrm{N}$ e de $\mathrm{K}$. 
Na Figura 5B pode-se observar que a maior área foliar $(2139,9$ $\mathrm{cm}^{3}$ ) foi obtida, com as doses de 6,0 e 1,25 g por planta de $\mathrm{N}$ e de $\mathrm{K}$, respectivamente. Doses de $\mathrm{K}$ acima de $1,25 \mathrm{~g}$ por planta reduziram a área foliar. Essa interação entre $\mathrm{N}$ e K é semelhante à encontrada por Bernardi et al. (2000a), que obteve área foliar máxima de 2251,4 $\mathrm{cm}^{2}$ com doses de 6,9 e 6,32 g de $\mathrm{N}$ e $\mathrm{K}$ por planta, respectivamente. A maioria dos trabalhos tem encontrado correlações entre o aumento da área foliar em função das doses de $\mathrm{N}$ e não de K (Reese \& Koo, 1975; Maust \& Willianson, 1991). Esse efeito também pode ser observado na Figura 5B, pois mesmo com a menor dose de $\mathrm{K}$ ocorreu uma tendência linear muito forte, entre a área foliar e as doses de $\mathrm{N}$.

A

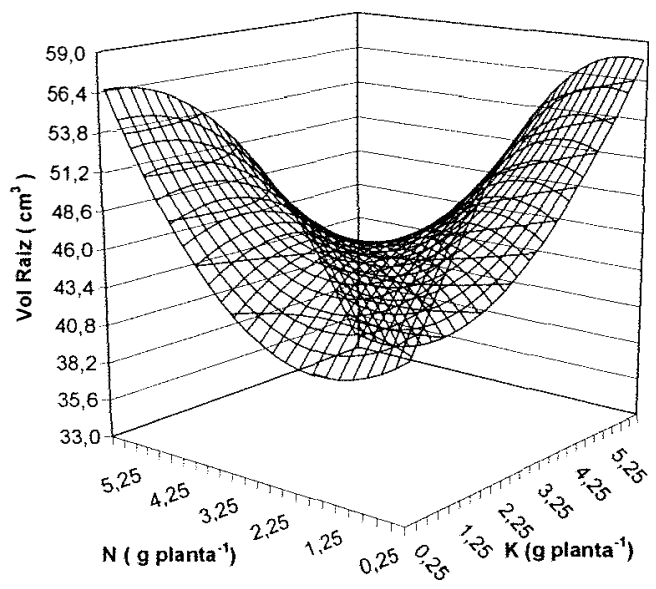

$\mathrm{Y}=0,92 \mathrm{~N}^{2}-3,151 \mathrm{~N}-0,68 \mathrm{~K}^{2}+7,08 \mathrm{~K}-1,114 \mathrm{KN}+42,214$ $\mathrm{R}^{2}=0,52$

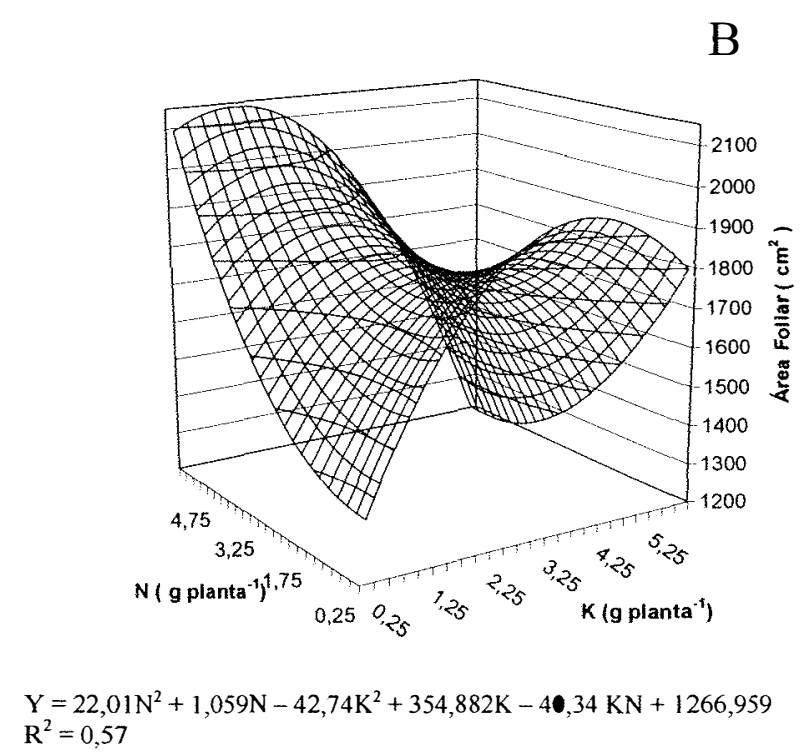

Figura 5 - Volume de raízes (A), área foliar (B) laranjeira 'Pêra' aos 6 meses após a enxertia. 


\subsection{Concentrações foliares}

A melhor correlação entre concentração foliar e estado nutricional da planta ocorre em tecidos maduros ou seja, nas folhas totalmente desenvolvidas, que estão nutricionalmente equilibradas (Malavolta et al., 1997).

Observou-se interação entre a adubação com $\mathrm{N}$ e $\mathrm{P}$ sobre as concentrações de $\mathrm{N}$ nas folhas do limoeiro 'Cravo' aos 5 meses após o transplante. A concentração máxima de $\mathrm{N}\left(40,56 \mathrm{~g} \mathrm{~kg}^{-1}\right)$ foi obtida com as doses de 4,0 e de 2,10 g por planta de $\mathrm{N}$ e de $\mathrm{P}$, respectivamente (Figura 6A). Com a utilização dessas doses de $\mathrm{N}$ e de $\mathrm{P}$, as concentrações foliares de $\mathrm{N}$ situaram-se na faixa de concentração excessivas, uma vez que as concentrações adequadas variam de 23 à $27 \mathrm{~g} \mathrm{~kg}^{-1}$ (GPACC, 1994). Este resultado concorda com o de Bernardi (1999), que também ultrapassou a concentração considerada como adequada, com doses de $\mathrm{N}$ acima de $1 \mathrm{~g}$ por planta. Entretanto, vários autores descreveram que as concentrações de $\mathrm{N}$ não são influenciados pela adubação fosfatada (Vichiato, 1996; Souto, 1993; Paula, 1991; Souza, 1990; Bueno, 1984). Alguns autores citam reduções nas concentrações de $\mathrm{N}$ em função das doses de fertilizantes fosfatados em pomares adultos e em formação (Gallo et al. 1960; Reese \& Koo, 1975; Souza, 1983), em sementeira

(Nicoli et al., 1986; Carvalho \& Souza, 1987; Fontanezzi, 1989) e em vasos (Fonseca et al., 1994).

Para as concentrações de $\mathrm{N}$ nas folhas da laranjeira 'Pêra' aos 6 meses após a enxertia, pode-se verificar um efeito quadrático das concentrações foliares de $\mathrm{N}$ em função das doses de $\mathrm{N}$ empregadas (Tabela 4). Obteve-se variações na concentração de $\mathrm{N}$ que estiveram 
entre 25,9 a 37,7 $\mathrm{g} \mathrm{kg}^{-1}$ (Figura 6B). Com doses estimadas iguais ou superiores a $1,75 \mathrm{~g}$ por planta de $\mathrm{N}$, já se estaria atingindo concentrações considerados como excessivos (>30) pelo GPACC (1994) pois, as concentrações como adequadas de $\mathrm{N}$ situam-se na faixa de 23 $27 \mathrm{~g} \mathrm{~kg}^{-1}$. Resultados positivos na concentração de $\mathrm{N}$ nas folhas, devido à adição de fertilizantes nitrogenados são relatados por Carvalho (1994b), Maust \& Williamson (1991) e Teng \& Timmer (1994).

Tabela 4. Função de resposta das variáveis concentração de macronutrientes nas folhas, ajustadas para termos significativos obtidos para o limoeiro 'Cravo' e para as mudas de laranja 'Pêra'. As condições indicam os niveis dos nutrientes não significativos para os quais as equações foram ajustadas.

\begin{tabular}{|c|c|c|c|}
\hline Variável & Equação & Condição (g) & $\mathbf{R}^{2}$ \\
\hline \multicolumn{4}{|l|}{ Limoeiro } \\
\hline$N$ & $\mathrm{Y}=-0,7956 \mathrm{~N}^{2}+7,5613 \mathrm{~N}-1,1424 \mathrm{P}^{2}+7,2802 \mathrm{P}-0,5643 \mathrm{PN}+17,5372$ & $\mathrm{~K}=0,4$ e $\mathrm{Ca}=3,5$ & 0,82 \\
\hline $\mathrm{P}$ & $\mathrm{Y}=-0,2268 \mathrm{P}^{2}+2,1523 \mathrm{P}+0,0125 \mathrm{Ca}^{2}-0,0556 \mathrm{Ca}-0,073 \mathrm{lCaP}+1,3916$ & $\mathrm{~N}=0,06 \mathrm{e} \mathrm{K}=0,4$ & 0,91 \\
\hline K & $\mathrm{Y}=-0,5766 \mathrm{P}^{2}+2,3116 \mathrm{P}-0,4817 \mathrm{~K}^{2}+4,4551 \mathrm{~K}+0,1364 \mathrm{KP}+14,4111$ & $\mathrm{Ca}=3,5$ e $\mathrm{N}=0,06$ & 0,92 \\
\hline $\mathrm{Ca}$ & $Y=-1,0134 \mathrm{~N}^{2}+7,0691 \mathrm{~N}+14,6813$ & $P=0,35, K=0,4 \mathrm{e}$ & 0,78 \\
\hline & & $\mathrm{Ca}=3,5$ & \\
\hline $\mathrm{Mg}$ & $\mathrm{Y}=0,0903 \mathrm{~K}^{2}-0,7975 \mathrm{~K}+0,0701 \mathrm{Ca}^{2}-0,6228 \mathrm{Ca}+0,0285 \mathrm{CaK}+4,2021$ & $\mathrm{P}=0,35$ e $\mathrm{N}=0,06$ & 0,84 \\
\hline S & $Y=-0,1245 P^{2}+1,1679 P+0,0523 \mathrm{Ca}^{2}+0,0675 \mathrm{Ca}-0,097 \mathrm{CaP}+1,3086$ & $\mathrm{~K}=0,4$ e $N=0,06$ & 0,85 \\
\hline \multicolumn{4}{|l|}{ Laranjeira } \\
\hline $\mathrm{N}$ & $Y=-0,195 N^{2}+3,267 N+25,108$ & $\mathrm{~K}=0,37$ e $\mathrm{Ca}=0,6$ & 0,91 \\
\hline $\mathrm{P}$ & $\mathrm{Y}=0,024 \mathrm{~N}^{2}-0,032 \mathrm{~N}+1,995$ & $\mathrm{~K}=0,37$ e $\mathrm{Ca}=0,6$ & 0,81 \\
\hline $\mathrm{K}$ & $Y=0,293 \mathrm{Ca}^{2}-3,791 \mathrm{Ca}+24,601$ & $\mathrm{~N}=0,37$ e $\mathrm{K}=0,37$ & 0,81 \\
\hline
\end{tabular}


A

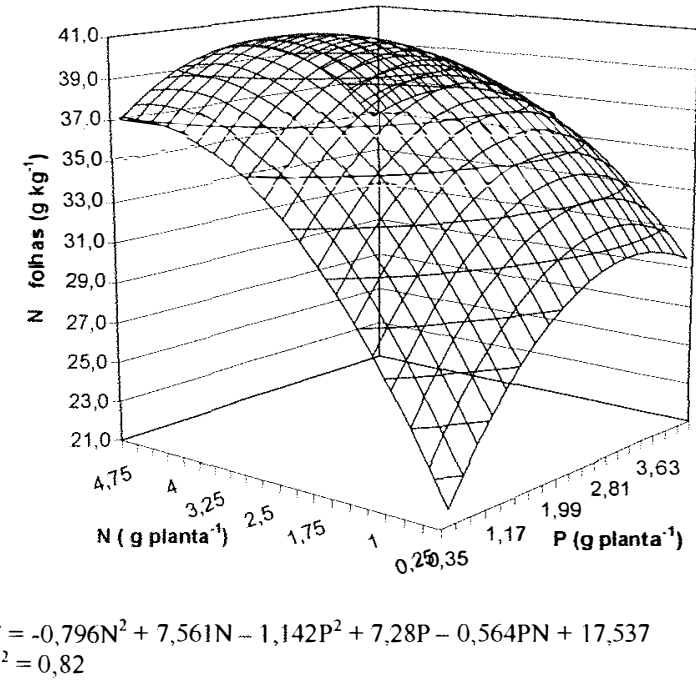

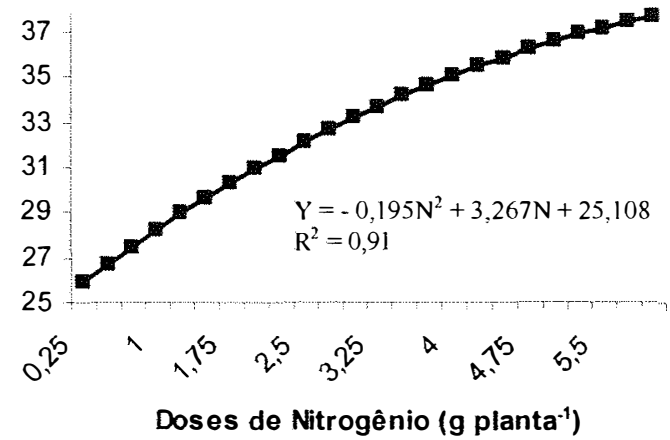

Figura 6 - Concentração de $\mathrm{N}$ nas folhas do limoeiro 'Cravo' (A) aos 5 meses após o transplante e da laranjeira 'Pêra' (B) aos 6 meses após a enxertia.

Quanto as concentrações foliares de P no limoeiro 'Cravo' aos 5 meses após o transplante houve interação entre $\mathrm{P}$ e $\mathrm{Ca}$, no qual a participação do Ca é pouco significativa, pois aumentando-se a dose de $\mathrm{Ca}$ de 3,5 para 8,0 g por planta, indiferente da doses de $\mathrm{P}$, a concentração foliar de $\mathrm{P}$ é praticamente constante (Figura 7A). A maior concentração foliar de $\mathrm{P}\left(5,3 \mathrm{~g} \mathrm{~kg}^{-1}\right)$ foi obtido com a maior dose de $\mathrm{P}$ (4 g por planta) entretanto, essa concentração é considerada excessiva. A concentração foliar de $\mathrm{P}$ está dentro das concentrações consideradas como adequadas propostos pelo GPACC (1994), entre 1,2 e 1,6 $\mathrm{g} \mathrm{kg}^{-1}$, obtidos com as doses mínimas de 0,35 e 3,5 g por planta de $\mathrm{P}$ e $\mathrm{Ca}$, respectivamente. Esses resultados concordam com os de Bernardi (1999), que observou aumentos nas concentrações foliares, com o 
aumento da dose de P. Entretanto, as concentrações também foram consideradas excessivas.

$\mathrm{Na}$ Figura 7B observa-se um efeito quadrático entre as concentrações foliares de P na laranjeira 'Pêra' e as doses de fertilizante nitrogenado. Das concentrações foliares de $\mathrm{P}$ somente os obtidos com doses que variaram de 0,25 - 2,75 g por planta de $\mathrm{N}$ estão dentro da faixa considerada como adequada, pois acima dessas doses, a concentração de $\mathrm{P}$ nas folhas situou-se na faixa considerada excessiva $\left(>2,0 \mathrm{~g} \mathrm{~kg}^{-1}\right.$ de P). Esses resultados concordam com os de Bernardi et al. (2000b) que, também atingiram concentrações excessivas, chegando a uma concentração máxima de 3,55 $\mathrm{g} \mathrm{kg}^{-1}$ com doses de 8,01 e 2,38 g por planta de $\mathrm{N}$ e de $\mathrm{P}$, respectivamente.

Acréscimos nas concentrações foliares de $\mathrm{P}$, como efeito da adubação nitrogenada, foi constatado por Locatelli (1984). Doses elevadas de $\mathrm{N}$ podem tornar o $\mathrm{P}$ mais disponivel, influenciando a sua absorção pelas plantas (Lopes, 1989). Esse efeito pode ser atribuído à maior crescimento das raízes, à mudanças na disponibilidade do $\mathrm{P}$ ou mudanças fisiológicas na planta (Miller et al, 1970 e Smith \& Jackson, 1987). Esses resultados discordam de Smith (1966) que, utilizando nitrato de amônio, encontrou decréscimo nas concentrações de $\mathrm{P}$ em função de doses de N. 


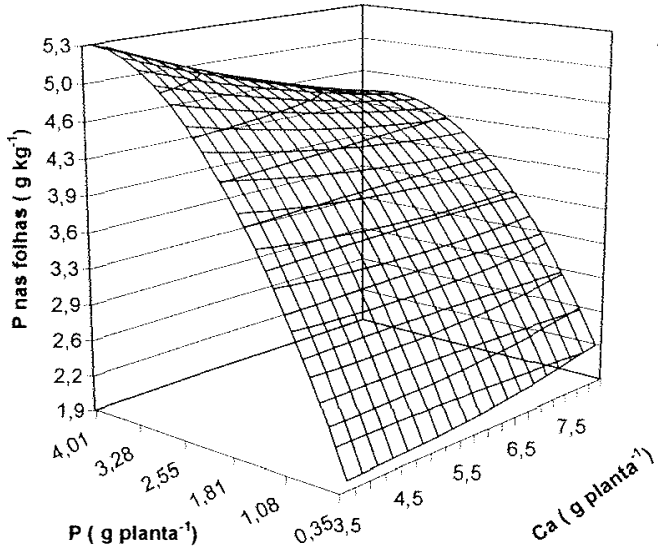

A

$\mathrm{B}$

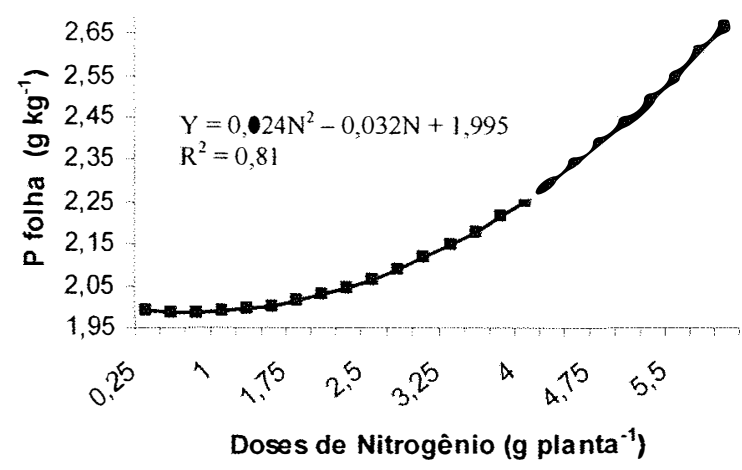

$\mathrm{Y}=-0,2268 \mathrm{P}^{2}+2,1523 \mathrm{P}+0,0125 \mathrm{Ca}^{2}-0,0556 \mathrm{Ca}-0,0731 \mathrm{CaP}+1,3916$ $\mathrm{R}^{2}=0,91$

Figura 7 - Concentrações de P nas folhas do limoeiro 'Cravo' (A) aos 5 meses após o transplante e da laranjeira 'Pêra' (B) aos 6 meses após a enxertia.

Quanto às concentrações foliares de $\mathrm{K}$ do porta-enxerto limoeiro 'Cravo', observou-se interação com a adubação com P e K (Figura 8A). A concentração foliar máxima de $\mathrm{K}\left(28,53 \mathrm{~g} \mathrm{~kg}^{-1}\right)$ foi obtida com as doses de 2,59 e 4,99 g por planta de $\mathrm{P}$ e de $\mathrm{K}$, respectivamente. Concentrações médias de $\mathrm{K}$ na MS do porta-enxerto, segundo vários autores (Nicoli et al., 1986; Bueno, 1984; Carvalho, 1994b; Rezende, 1991 e Souto, 1993), variaram entre 5,8 e $23 \mathrm{~g} \mathrm{~kg}^{-1}$; entretanto, essas concentrações são aos 4 meses após a semeadura. Bernardi et al. (2000b) obteve, para plantas aos 4 meses após o transplantio, concentração máxima de $33 \mathrm{~g} \mathrm{~kg}^{-1}$, com doses de 0,47 e 4,67 g de $\mathrm{N}$ e K por planta, respectivamente. 
Para as concentrações foliares de $\mathrm{K}$ da laranjeira 'Pêra' aos 6 meses após a enxertia ocorreu um efeito quadrático negativo entre a concentração de $\mathrm{K}$ e as doses de $\mathrm{Ca}$, mostrando a existência de uma interação competitiva entre o $\mathrm{Ca}$ e o $\mathrm{K}$, onde o aumento nas doses de $\mathrm{Ca}$ diminuem a concentração de $\mathrm{K}$ nas folhas (Marschner, 1995; Chapmann, 1968). Entretanto, as concentrações de K estão acima da faixa considerada adequada (12 - $\left.15 \mathrm{~g} \mathrm{~kg}^{-1}\right)$ com concentrações que variaram de 22,4 a 15,9 $\mathrm{g} \mathrm{kg}^{-1}$ de $\mathrm{K}$ para as doses de 0,6 a $3 \mathrm{~g}$ por planta de Ca (Figura 8B).
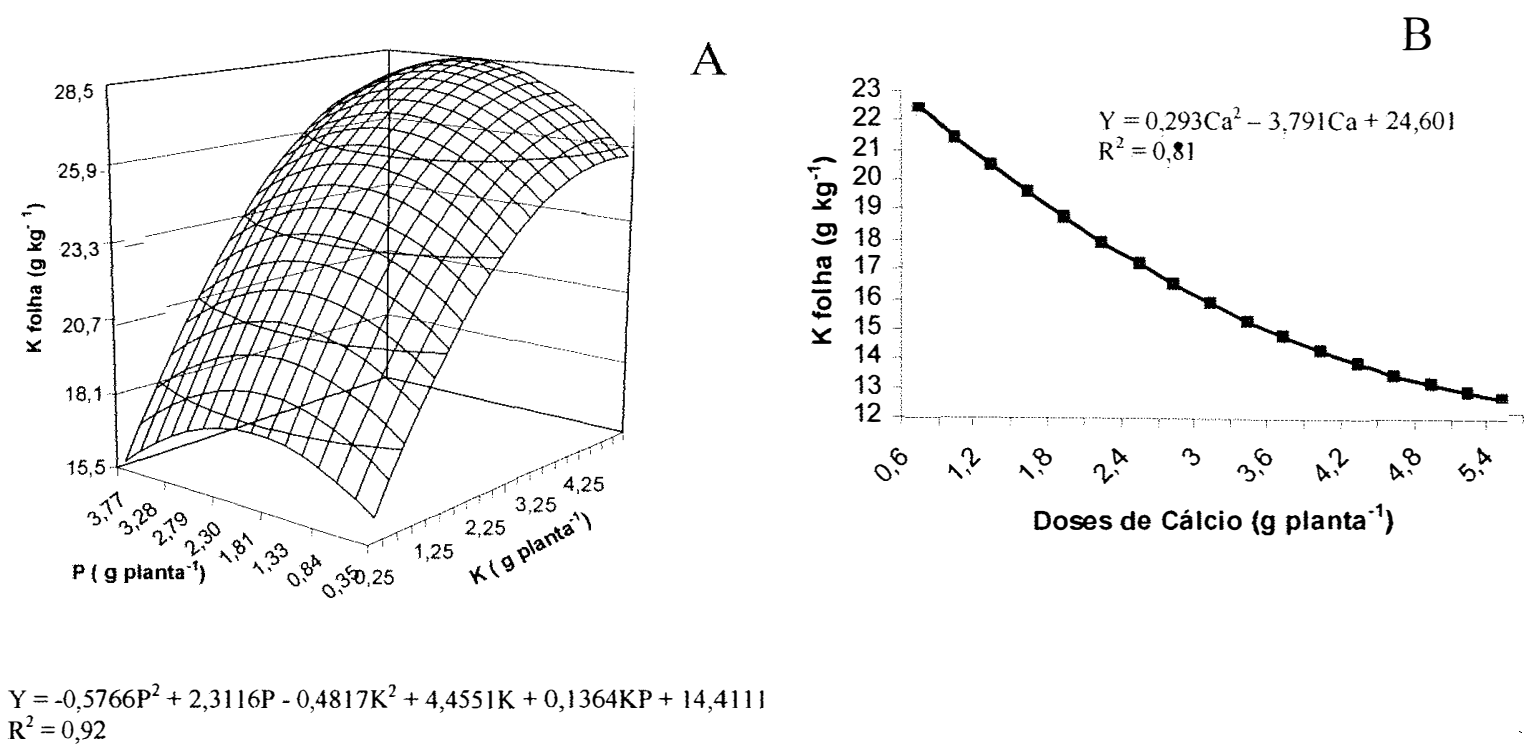

Figura 8 - Concentração de $\mathrm{K}$ nas folhas do limoeiro 'Cravo' (A) aos 5 meses após o transplante e da laranjeira 'Pêra' (B) aos 6 meses após a enxertia.

Para concentrações foliares de Ca no limoeiro 'Cravo' aos 5 meses após o transplante, ocorreu um efeito quadrático entre as concentrações foliares de $\mathrm{Ca}$ e as doses de $\mathrm{N}$ aplicadas, sendo a 
concentração máxima $\left(27,0 \mathrm{~g} \mathrm{~kg}^{-1}\right)$ obtido com a dose de 3,49 g por planta de $\mathrm{N}$ (Figura 9). As concentrações foliares de Ca estão dentro da faixa considerada como baixa pois, as concentrações adequadas variam de 35-45 (GPACC, 1994) ou de 30-49 (Malavolta et al., 1997). Entretanto, Castle \& Rouse (1990) encontraram valores menores $(10,9 \mathrm{~g}$ $\mathrm{kg}^{-1}$ ) para as mudas.

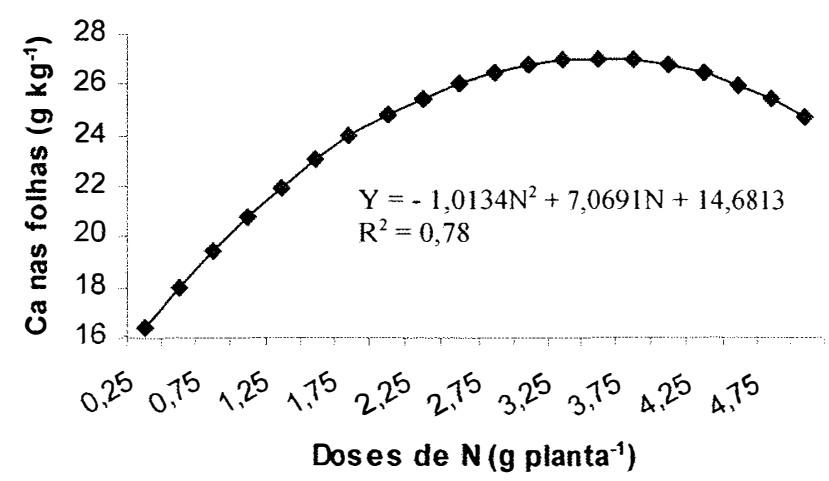

Figura 9 - Concentração de Ca nas folhas do limoeiro 'Cravo' aos 5 meses após o transplante.

Essas concentrações foliares baixas poderiam ser explicados pela inibição competitiva entre $\mathrm{K}$ e $\mathrm{Ca}$ pois, a presença de altas doses de $\mathrm{K}$ inibem a absorção de Ca (Chapmann, 1968; Marschner, 1995; Malavolta et al., 1997). Isso está bem evidenciado pelas concentrações foliares altos de K. (Figura 8A). Bernardi (1999) obteve uma redução nas concentrações foliares de $\mathrm{Ca}$ na presença de doses altas de $\mathrm{N}$, com valores que variaram de 16,5 até $20,7 \mathrm{~g} \mathrm{~kg}^{-1}$ de Ca. Essa redução nas concentrações foliares de Ca em função de altas doses de $\mathrm{N}$ também foi observado por Koo \& Reese (1977), Serna et al. (1992) e Carvalho 
(1994b). Este efeito poderia ser explicado pela inibição da absorção do $\mathrm{Ca}^{++}$quando uma fonte nitrogenada com $\mathrm{NH}_{4}{ }^{+}$é utilizada. Entretanto, Vichiato (1996) não encontrou efeito entre a adubação nitrogenada e as concentrações de Ca na MS do limoeiro 'Cravo'. As concentração foliares de Ca em laranjeira 'Pêra' aos 6 meses após a enxertia não tiveram relação com os tratamentos empregados.

Na Figura 10 verifica-se que as concentrações de $\mathrm{Mg}$ nas folhas do limoeiro 'Cravo' aos 5 meses após o transplante diminuem com o aumento das doses de $\mathrm{K}$, demonstrando assim, uma inibição competitiva entre o $\mathrm{K}$ e o $\mathrm{Mg}$, que já havia sido relatada por Anderson (1987), Marschner (1995), Malavolta et al. (1997). Doses de K acima de 1,5 g por planta, nesse experimento, reduziram as concentrações de $\mathrm{Mg}$ nas folhas, fazendo com que ficassem abaixo das concentrações consideradas adequados $(2,5-4,0)$ do GPACC (1994), porém sem demonstrarem sintoma visual de deficiência. Diversos autores encontraram valores médios de $\mathrm{Mg}$ em limoeiro 'Cravo', que variaram de 0,7 a 5,2 $\mathrm{g} \mathrm{kg}^{-1}$ (Silva, 1981; Camargo et al., 1990; Souza, 1990). Em mudas de viveiro, Castle \& Rouse (1990) encontraram concentrações médias de $\mathrm{Mg}$ de $1,5 \mathrm{~g} \mathrm{~kg}^{-1}$. 


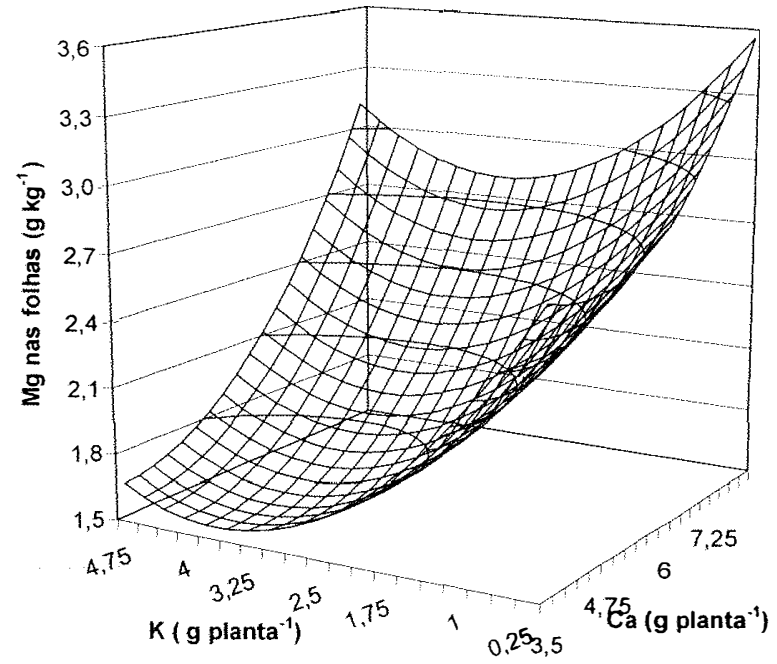

$Y=0,0903 \mathrm{~K}^{2}-0,7975 \mathrm{~K}+0,0701 \mathrm{Ca}^{2}-0,6228 \mathrm{Ca}+0,0285 \mathrm{CaK}+4,2021$
$\mathrm{R}^{2}=0,84$

Figura 10 - Concentração de Mg nas folhas do limoeiro 'Cravo' aos 5 meses após o transplante.

Houve interação entre as doses $\mathrm{P}$ e $\mathrm{Ca}$ aplicadas $\mathrm{e}$ as concentrações de $\mathrm{S}$ nas folhas do limoeiro 'Cravo' (Figura 11). A concentração máxima nas folhas $\left(5,4 \mathrm{~g} \mathrm{~kg}^{-1}\right)$ foi obtido com a maior dose de $\mathrm{Ca}$, provavelmente devido à fonte de $\mathrm{Ca}$ ser o gesso agrícola, que possui $16 \%$ de $\mathrm{S}$ (Vitti, et al. 1996). Isto pode ser verificado na Figura 11, através do efeito positivo das concentrações de $\mathrm{S}$, em função das doses de Ca. Mesmo nas doses mínimas de $\mathrm{P}$ e de $\mathrm{Ca}$ as concentrações foliares de $\mathrm{S}$ nas folhas já se encontram na faixa considerada como adequada (2,0-3,0), segundo GPACC (1994). 


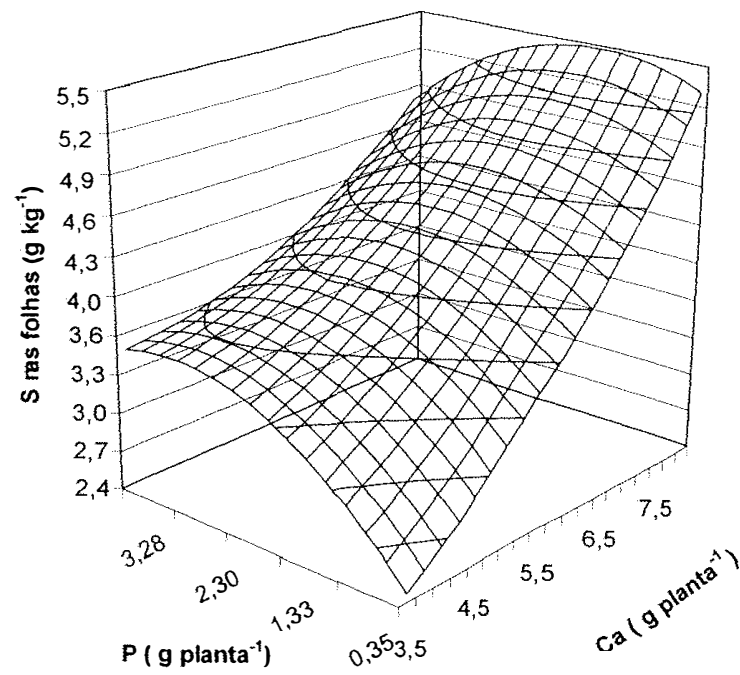

$Y=-0,1245 P^{2}+1,1679 P+0,0523 \mathrm{Ca}^{2}+0,0675 \mathrm{Ca}-0,097 \mathrm{CaP}+1,3086$
$R^{2}=0,85$

Figura 11 - Concentração de S nas folhas do limoeiro 'Cravo' aos 5 meses após o transplante.

\subsection{Nutrientes acumulados}

$\mathrm{O}$ acúmulo de $\mathrm{N}$ pelos tecidos analisados do porta-enxerto Limoeiro 'Cravo' seguiu a seguinte ordem decrescente: Folha > Raízes > Caule.

Para o acúmulo de $\mathrm{N}$ pelas folhas do limoeiro 'Cravo' houve interação entre a adubação com N e K (Figura 12A). O acúmulo máximo aos 5 meses foi de 0,326 g de $\mathrm{N}$, nas doses de 5,00 e de 1,58 g por planta de $\mathrm{N}$ e de $\mathrm{P}$, respectivamente. Para as demais partes da planta (Figura 12B, Figura 12C), bem como no acúmulo total (Figura 12D) houve efeito quadrático das doses de $\mathrm{N}$ sobre o acúmulo de $\mathrm{N}$. Os acúmulos máximos para o caule, as raízes e o total foram de 0,121 , 0,140 e 0,612 g de $\mathrm{N}$ com as doses de 4,81, 4,22 e 5,00 g por planta, respectivamente. 


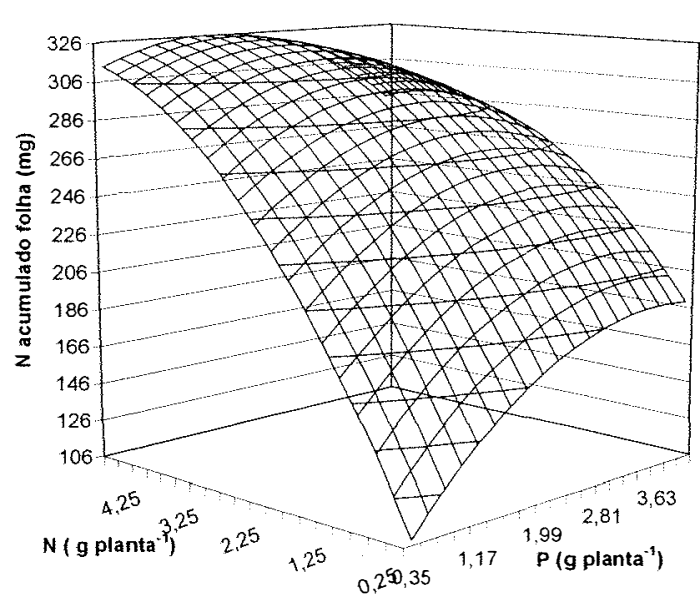

A

$\mathrm{B}$

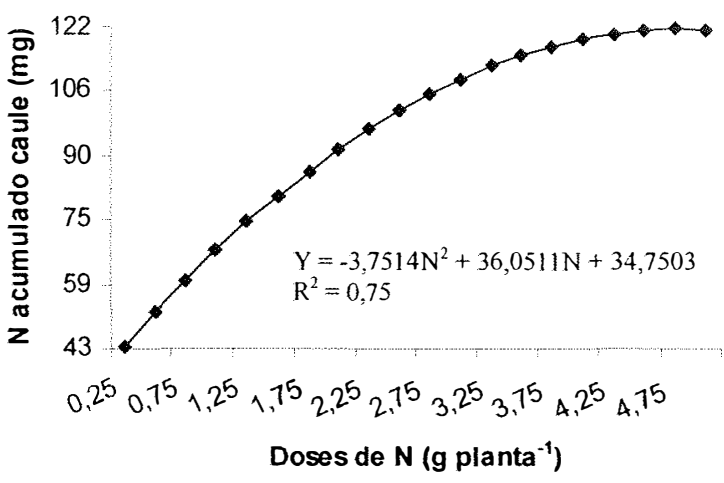

$Y=-6,7365 N^{2}+80,629 N-7,6873 P^{2}+57,379 P-6,306 P N+69,744$ $R^{2}=0,85$

C $\mathrm{D}$
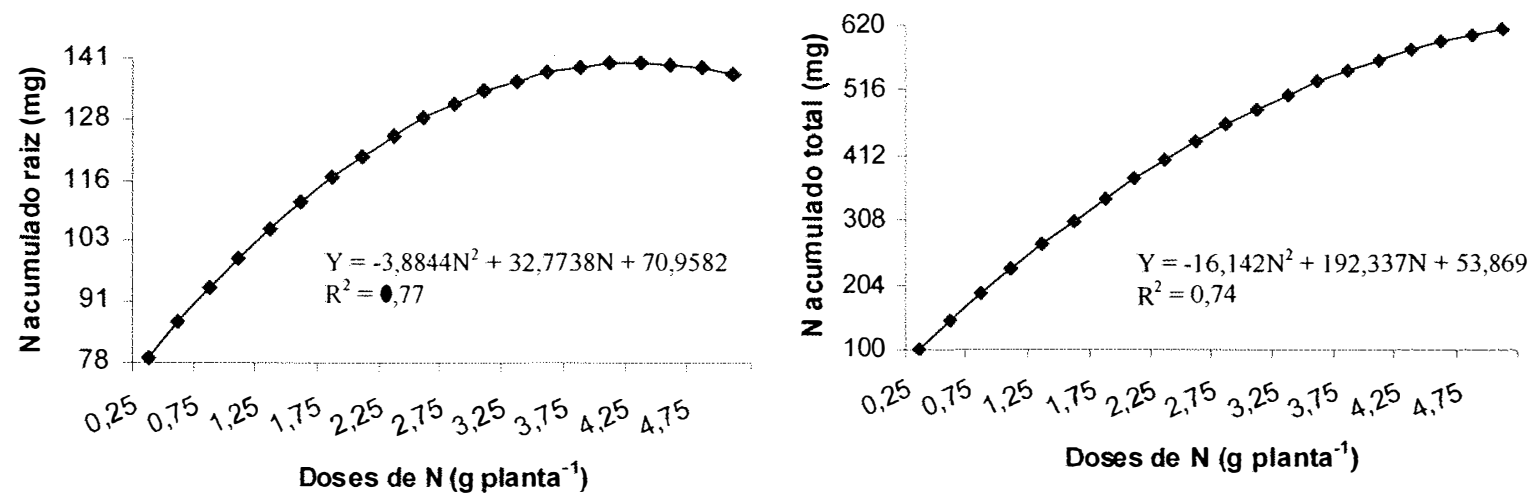

Figura 12 - Quantidade de $\mathrm{N}$ acumulado pelo limoeiro 'Cravo' aos 5 meses após o transplante: folhas $(\mathrm{A})$, caule $(\mathrm{B})$, raízes $(\mathrm{C})$ e total (D).

$\mathrm{O}$ acúmulo de $\mathrm{N}$ nas raízes e caule são de grande importância, pois poderá ser retranslocado para partes as novas em desenvolvimento e para o enxerto (Legaz et al., 1995). A quantidade acumulada na parte aérea da planta corresponde a $73 \%$ do total acumulado em todos os 
tecidos. Isso evidencia o papel positivo do $\mathrm{N}$, no crescimento e no metabolismo vegetal.

Para a laranjeira 'Pêra' aos 6 meses após a enxertia, as equações obtidas para as relações entre os tratamentos e o acúmulo dos macronutrientes estão na Tabela 5.

Tabela 5 - Função de resposta das variáveis acúmulo de macronutrientes ajustadas para termos significativos obtidos para limoeiro 'Cravo' e para mudas de laranja 'Pêra'. As condições indicam os niveis dos nutrientes não significativos para os quais as equações foram ajustadas.

\begin{tabular}{|c|c|c|c|}
\hline Variável & Equação & Condição (g) & $\mathbf{R}^{2}$ \\
\hline \multicolumn{4}{|c|}{ Limoeiro 'Cravo' } \\
\hline $\mathrm{N}$ folha & $\mathrm{Y}=-6,736 \mathrm{~N}^{2}+80,62 \mathrm{~N}-7,687 \mathrm{P}^{2}+57,37 \mathrm{P}-6,306 \mathrm{PN}+69,744$ & $\mathrm{~K}=0,4$ e $\mathrm{Ca}=3,5$ & 0,85 \\
\hline P folha & $\mathrm{Y}=-0,1936 \mathrm{~N}^{2}+3,412 \mathrm{~N}-1,588 \mathrm{P}^{2}+13,552 \mathrm{P}-0,493 \mathrm{PN}+4,437$ & $\mathrm{~K}=0,4 \mathrm{e} \mathrm{Ca}=3,5$ & 0,89 \\
\hline $\mathrm{K}$ folha & $Y=-2,2768 K^{2}+25,596 \mathrm{~K}+70,4414$ & $\mathrm{~N}=0,06, \mathrm{Ca}=3,5 \mathrm{e} \mathrm{P}=0,35$ & 0,85 \\
\hline Ca folha & $\mathrm{Y}=-8,416 \mathrm{~N}^{2}+74,127 \mathrm{~N}+5,11 \bullet \mathrm{K}^{2}-35,623 \mathrm{~K}-3,811 \mathrm{KN}+80,129$ & $\mathrm{P}=0,35$ e $\mathrm{Ca}=3,5$ & 0,81 \\
\hline $\mathrm{Mg}$ folha & $Y=-1,0678 N^{2}+9,974 N+0,905 K^{2}-6,338 K-0,231 K N+14,049$ & $\mathrm{P}=0,35$ e $\mathrm{Ca}=3,5$ & 0,87 \\
\hline$S$ folha & $\mathrm{Y}=0,4617 \mathrm{~N}^{2}-1,013 \mathrm{~N}-0,027 \mathrm{Ca}^{2}+5,066 \mathrm{Ca}-0,530 \mathrm{CaN}-4,819$ & $K=0,4$ e $P=0,35$ & 0,71 \\
\hline $\mathrm{N}$ caule & $\mathrm{Y}=-3,7514 \mathrm{~N}^{2}+36,0511 \mathrm{~N}+34,7503$ & $P=0,35, C a=3,5$ e $K=0,4$ & 0,75 \\
\hline P caule & $\mathrm{Y}=-0,466 \mathrm{~N}^{2}+4,344 \mathrm{~N}-1,491 \mathrm{P}^{2}+12,171 \mathrm{P}-0,385 \mathrm{PN}-3,985$ & $\mathrm{~K}=0,4 \mathrm{e} \mathrm{Ca}=3,5$ & 0,88 \\
\hline K caule & $\mathrm{Y}=-1,522 \mathrm{~K}^{2}+19,357 \mathrm{~K}-2,662 \mathrm{Ca}^{2}+34,234 \mathrm{Ca}-1,09 \mathrm{CaK}-52,99$ & $\mathrm{~N}=0,06 \mathrm{e} P=0,35$ & 0,70 \\
\hline Ca caule & $\mathrm{Y}=-2,79 \mathrm{~N}^{2}+22,61 \mathrm{~N}-1,284 \mathrm{Ca}^{2}+16,518 \mathrm{Ca}-0,09 \mathrm{CaN}-32,74$ & $K=0,40$ e $P=0,35$ & 0,82 \\
\hline Mg caule & $\mathrm{Y}=-1,1074 \mathrm{~N}^{2}+8,0517 \mathrm{~N}-0,5741 \mathrm{P}^{2}+4,1 \mathrm{P}-0,339 \mathrm{PN}+5,3772$ & $\mathrm{~K}=0,4 \mathrm{e} \mathrm{Ca}=3,5$ & 0,85 \\
\hline S caule & $\mathrm{Y}=0,0246 \mathrm{~N}^{2}+0,81 \mathrm{~N}-0,072 \mathrm{Ca}^{2}+2,138 \mathrm{Ca}-0,228 \mathrm{CaN}-2,839$ & $\mathrm{~K}=0,40$ e $\mathrm{P}=0,35$ & 0,51 \\
\hline $\mathrm{N}$ raiz & $Y=-3,8844 N^{2}+32,7738 N+70,9582$ & $\mathrm{~K}=0,4, \mathrm{Ca}=3,5$ e $\mathrm{P}=0,35$ & 0,77 \\
\hline P raiz & $\mathrm{Y}=0,571 \mathrm{P}^{2}+6,265 \mathrm{P}+0,662 \mathrm{~K}^{2}-1,837 \mathrm{~K}-1,196 \mathrm{KP}+7,569$ & $\mathrm{~N}=0,06 \mathrm{e} \mathrm{Ca}=3,5$ & 0,82 \\
\hline $\mathrm{K}$ raiz & $Y=-0,789 N^{2}-10,649 N+6,667 P^{2}-30,249 P+5,692 P N+198,811$ & $\mathrm{~K}=0,4 \mathrm{e} \mathrm{Ca}=3,5$ & 0,66 \\
\hline Mg raiz & $\mathrm{Y}=-1,518 \mathrm{~N}^{2}+8,229 \mathrm{~N}+0,404 \mathrm{~K}^{2}-3,546 \mathrm{~K}+0,334 \mathrm{KN}+12,041$ & $\mathrm{P}=0,35$ e $\mathrm{Ca}=3,5$ & 0,66 \\
\hline $\mathrm{S}$ raiz & $\mathrm{Y}=0,037 \mathrm{~N}^{2}+1,165 \mathrm{~N}-0,037 \mathrm{Ca}^{2}+7,013 \mathrm{Ca}-1,09 \mathrm{CaN}-8,7671$ & $K=0,40$ e $P=0,35$ & 0,67 \\
\hline $\mathrm{N}$ total & $Y==-16,1422 N^{2}+192,3376 N+53,869$ & $\mathrm{~K}==0,4, \mathrm{Ca}=3,5$ e $\mathrm{P}=0,35$ & 0,74 \\
\hline Ca total & $Y=-8,7284 N^{2}+70,0342 N+135,461$ & $\mathrm{~K}==0,4, \mathrm{Ca}=3,5$ e $\mathrm{P}=0,35$ & 0,56 \\
\hline \multicolumn{4}{|c|}{ Laranjeira 'Pêra' } \\
\hline N Total & $\mathrm{Y}=0,004 \mathrm{~N}^{2}+0,121 \mathrm{~N}-0,015 \mathrm{~K}^{2}+0,133 \mathrm{~K}-0,014 \mathrm{KN}+0,44$ & $\mathrm{Ca}=0,6$ & 0,90 \\
\hline N RAIZ & $\mathrm{Y}=-0,005 \mathrm{~K}^{2}+0,042 \mathrm{~K}+0,131$ & $\mathrm{~N}=0,37 \mathrm{e} \mathrm{Ca}=0,6$ & 0,87 \\
\hline P Total & $\mathrm{Y}=0,001 \mathrm{~N}^{2}+0,003 \mathrm{~N}-0,001 \mathrm{~K}^{2}+0,001 \mathrm{~K}-0,001 \mathrm{KN}+0,05$ & $\mathrm{Ca}=0,6$ & 0,76 \\
\hline P PA & $\mathrm{Y}=0,0006 \mathrm{~N}^{2}+0,003 \mathrm{~N}-0,0008 \mathrm{~K}^{2}+0,008 \mathrm{~K}-0,001 \mathrm{KN}+0,033$ & $\mathrm{Ca}=0,6$ & 0,81 \\
\hline S PA & $\mathrm{Y}=0,0004 \mathrm{~N}^{2}+0,003 \mathrm{~N}-0,0007 \mathrm{~K}^{2}+0,006 \mathrm{~K}-0,0008 \mathrm{KN}+0,032$ & $\mathrm{Ca}=0,6$ & 0,83 \\
\hline
\end{tabular}


Para o acúmulo total de $\mathrm{N}$, pela laranjeira 'Pêra' aos 6 meses após a enxertia, houve interação entre $\mathrm{N}$ e $\mathrm{K}$, obtendo-se um acúmulo total máximo de $\mathrm{N}(1,35 \mathrm{~g})$ com as doses de $6 \mathrm{~g}$ de $\mathrm{N}$ por planta e 1,75 g de $\mathrm{K}$ por planta (Figura $13 \mathrm{~A}$ ). Houve um efeito quadrático entre o acúmulo de $\mathrm{N}$ nas raízes $\mathrm{e}$ as doses da adubação potássica, demonstrando um efeito positivo entre a quantidade de $\mathrm{N}$ acumulada nas raizes e as doses de $\mathrm{K}$ aplicadas (Figura 13B e Tabela 5). Esse resultado concorda com o de Bernardi (1999) que encontrou resposta quadrática do acúmulo de $\mathrm{N}$ em função das doses de $\mathrm{N}$, obtendo 1,34 g como o valor máximo acumulado. Esse mesmo autor também encontrou interação entre o acúmulo total de $\mathrm{N}$ e as doses de $\mathrm{N}$ e de $\mathrm{K}$ porém, no limoeiro 'Cravo'.

A B
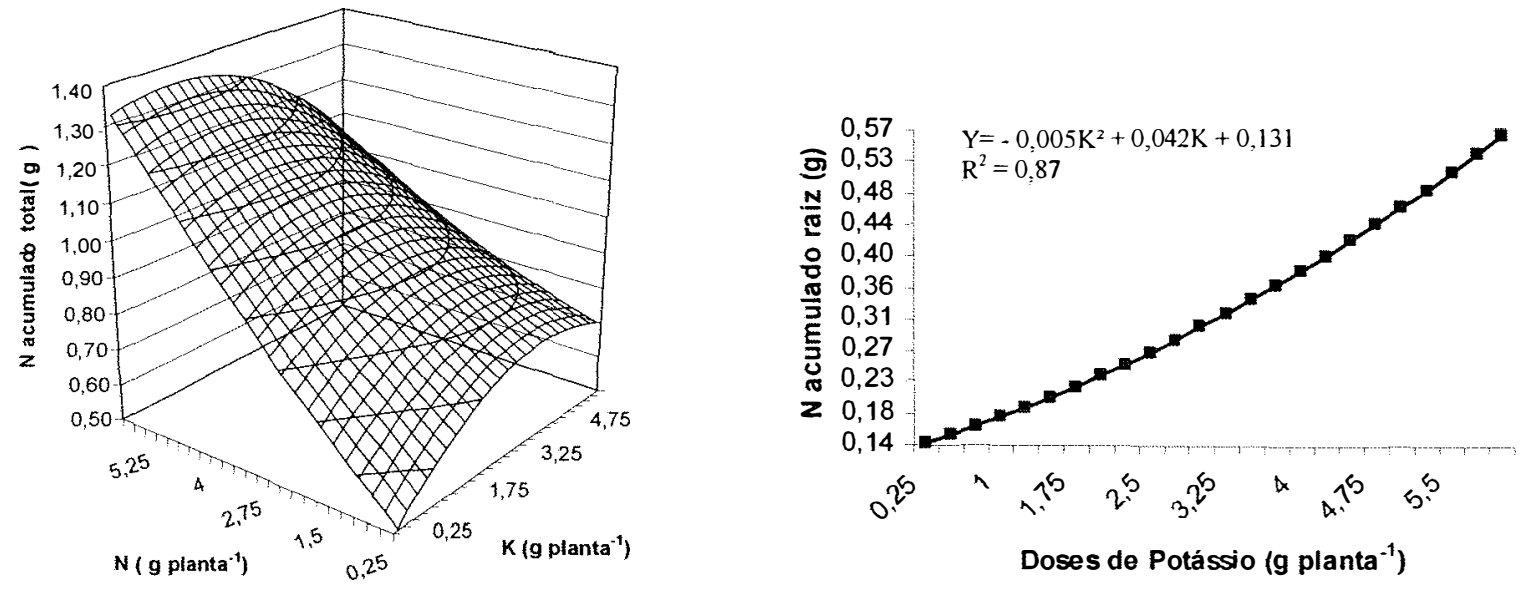

$Y=0,004 N^{2}+0,121 N-0,015 K^{2}+0,133 K-0,014 K N+0,44$ $\mathrm{R}^{2}=0,90$

Figura 13 - Acúmulo de $\mathrm{N}$ pela laranjeira 'Pêra' aos 6 meses após a enxertia :acúmulo total (A) e acúmulo nas raizes (B). 
Houve interação entre a fertilização com $\mathrm{N}$ e $\mathrm{P}$ no acúmulo de $\mathrm{P}$ pelas folhas e caule do limoeiro 'Cravo' aos 5 meses após o transplante (Figura 14A e Figura 14B). Os acúmulos máximos de P nas folhas (0,036 $\mathrm{g}$ de $\mathrm{P})$ e no caule $(0,025 \mathrm{~g}$ de $\mathrm{P})$ foram obtidas com as doses 4,2 e 3,61 e 3,14 e 3,67 g de $\mathrm{N}$ e de $\mathrm{P}$ por planta, respectivamente. Melloni et al. (2000) obteve acúmulo de 0,012 g de $\mathrm{P}$ na parte aérea do limoeiro 'Cravo', aos 5 meses após o transplantio, utilizando a dose de $\mathrm{P}$ igual a $250 \mathrm{mg} \mathrm{kg}^{-1}$ de substrato. Esse valor menor de $\mathrm{P}$ acumulado provavelmente tenha ocorrido devido ao tamanho menor do vaso utilizado $\left(1,7 \mathrm{dm}^{3}\right)$.

Na Figura 14C observa-se a interação negativa entre as doses do fertilizante potássico e o acúmulo de $\mathrm{P}$ nas raizes. $\mathrm{O}$ acúmulo máxima nas raizes foi de $0,04 \mathrm{~g}$ de $\mathrm{P}$, obtida com a dose maior de $\mathrm{P}$ e com a dose menor de K. A parte aérea acumulou $68 \%$ do total da planta. 
A

B

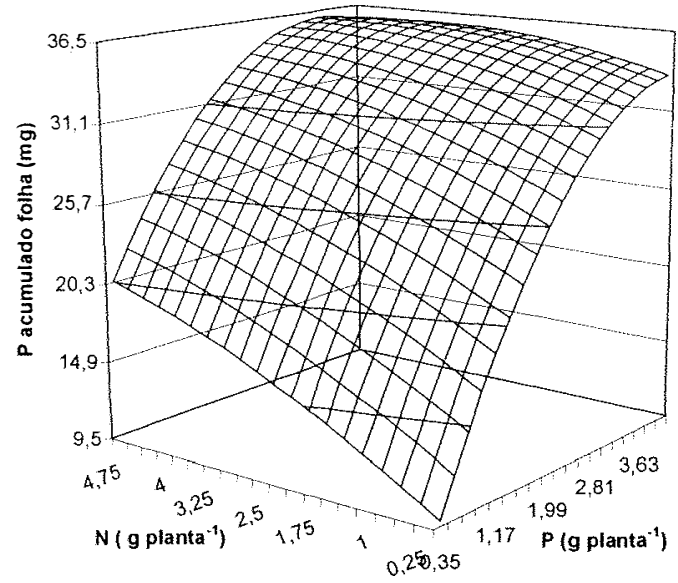

$\mathrm{Y}=-0,194 \mathrm{~N}^{2}+3,412 \mathrm{~N}-1,588 \mathrm{P}^{2}+13,553 \mathrm{P}-0,493 \mathrm{PN}+4,4369$ $\mathrm{R}^{2}=0,89$

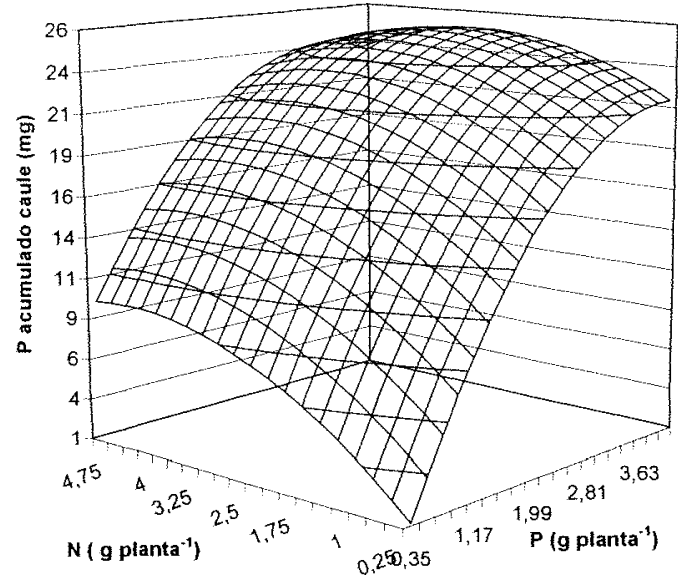

$\mathrm{Y}=-0,466 \mathrm{~N}^{2}+4,344 \mathrm{~N}-1,491 \mathrm{P}^{2}+12,171 \mathrm{P}-0,385 \mathrm{PN}-3,985$ $\mathrm{R}^{2}=0,88$

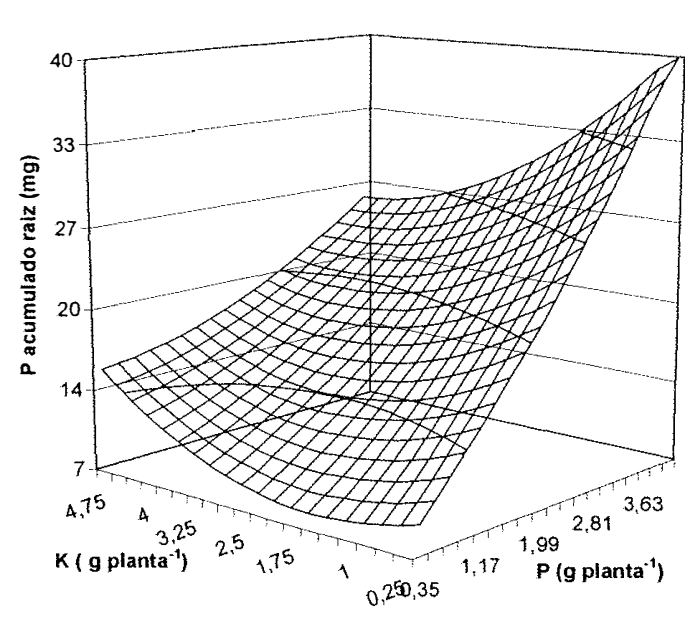

C

$Y=0,5714 \mathrm{P}^{2}+6,2655 \mathrm{P}+\boldsymbol{0}, 6625 \mathrm{~K}^{2}-1,8366 \mathrm{~K}-1,1956 \mathrm{KP}+7,5689$
$\mathrm{R}^{2}=0,82$

Figura 14 - Quantidade de P acumulado pelo limoeiro 'Cravo' aos 5 meses após o transplante: folhas (A), caule (B) e raizes (C).

As Figuras 15A e 15B ilustram o acúmulo de $\mathrm{P}$ na parte aérea e o total acumulado na planta, bem como a interação entre as doses de $\mathrm{N} \mathrm{e}$ de $\mathrm{K}$ e o acúmulo de $\mathrm{P}$ pela laranjeira 'Pêra', aos 6 meses após a 
enxertia. O acúmulo maior de $\mathrm{P}$ na parte aérea foi de $0,0739 \mathrm{~g}$ nas doses 6,0 e 1,25 g por planta de $\mathrm{N}$ e de $\mathrm{K}$, respectivamente (Figura $15 \mathrm{~A}$ ). No acúmulo de $\mathrm{P}$ na planta toda, a interação demonstrou um efeito positivo para o $\mathrm{N}$ e negativo para o $\mathrm{K}$ e, a quantidade máxima acumulada foi de 0,102 g por planta com as doses de 6,0 e 0,25 g por plana de $\mathrm{N}$ e de $\mathrm{K}$, respectivamente (Figura 15B). A parte aérea acumulou $72,5 \%$ do total da planta.

A

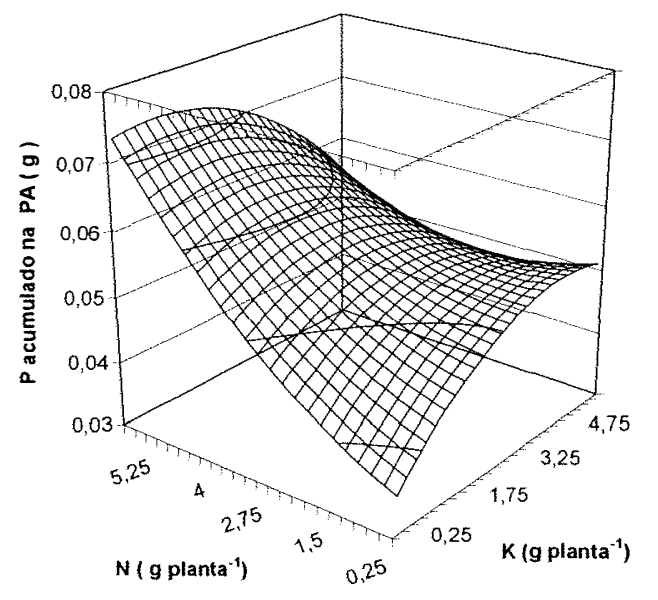

$\mathrm{Y}=0,0006 \mathrm{~N}^{2}+0,003 \mathrm{~N}-0,0008 \mathrm{~K}^{2}+0,008 \mathrm{~K}-0,001 \mathrm{KN}+0,033$ $\mathrm{R}^{2}=0,81$

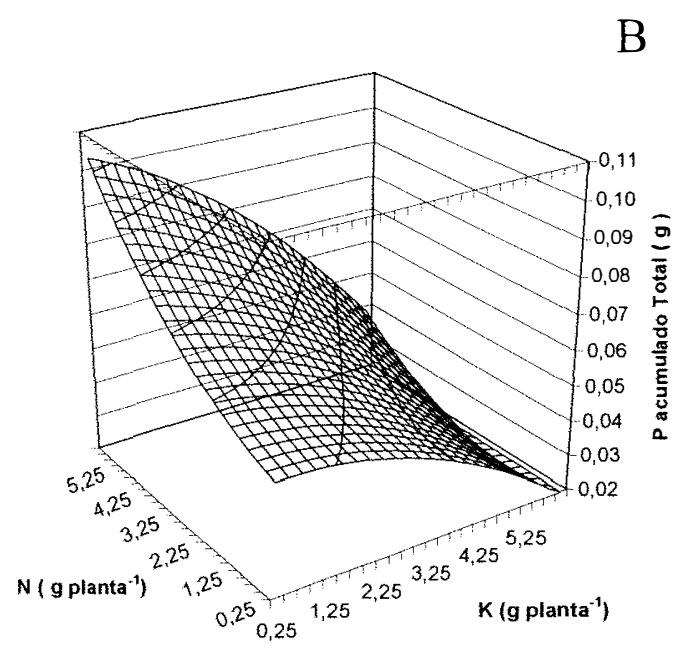

$\mathrm{Y}=0,001 \mathrm{~N}^{2}+0,003 \mathrm{~N}-0,001 \mathrm{~K}^{2}+0,001 \mathrm{~K}-0,001 \mathrm{KN}+0,05$ $R^{2}=0,76$

Figura 15 - Quantidade de P acumulado pela laranjeira 'Pêra' aos 6 meses após a enxertia: Parte aérea (A) e total da planta (B).

Para o acúmulo de $\mathrm{K}$ nas folhas do limoeiro 'Cravo' houve um efeito quadrático entre o acúmulo do nutriente e as doses aplicadas de $\mathrm{K}$ (Figura 16A) com um acúmulo máximo de 0,141 g de $\mathrm{K}$, com a dose de $5,00 \mathrm{~g}$ de $\mathrm{K}$ por planta. No caule, houve interação entre as doses de $\mathrm{K} \mathrm{e}$ $\mathrm{Ca}$, com um acúmulo máximo $(0,84 \mathrm{~g}$ de $\mathrm{K})$ nas doses 4,38 e 5,53 g por planta de $\mathrm{K}$ e de $\mathrm{Ca}$, respectivamente (Figura 16B). O acúmulo de $\mathrm{K}$ pela parte aérea corresponde a $58 \%$ do total. 
A parte da planta que mais acumulou $\mathrm{K}$ foi o sistema radical $(0,165 \mathrm{~g}$ de $\mathrm{K})$, com as doses de 0,6 e 2,03 g por planta de $\mathrm{N}$ e de $\mathrm{P}$, respectivamente. $\mathrm{O} \mathrm{N}$ teve um efeito negativo no acúmulo do $\mathrm{K}$ nas raízes, diminuindo seu acúmulo com o aumento da doses desse fertilizante (Figura 16C).
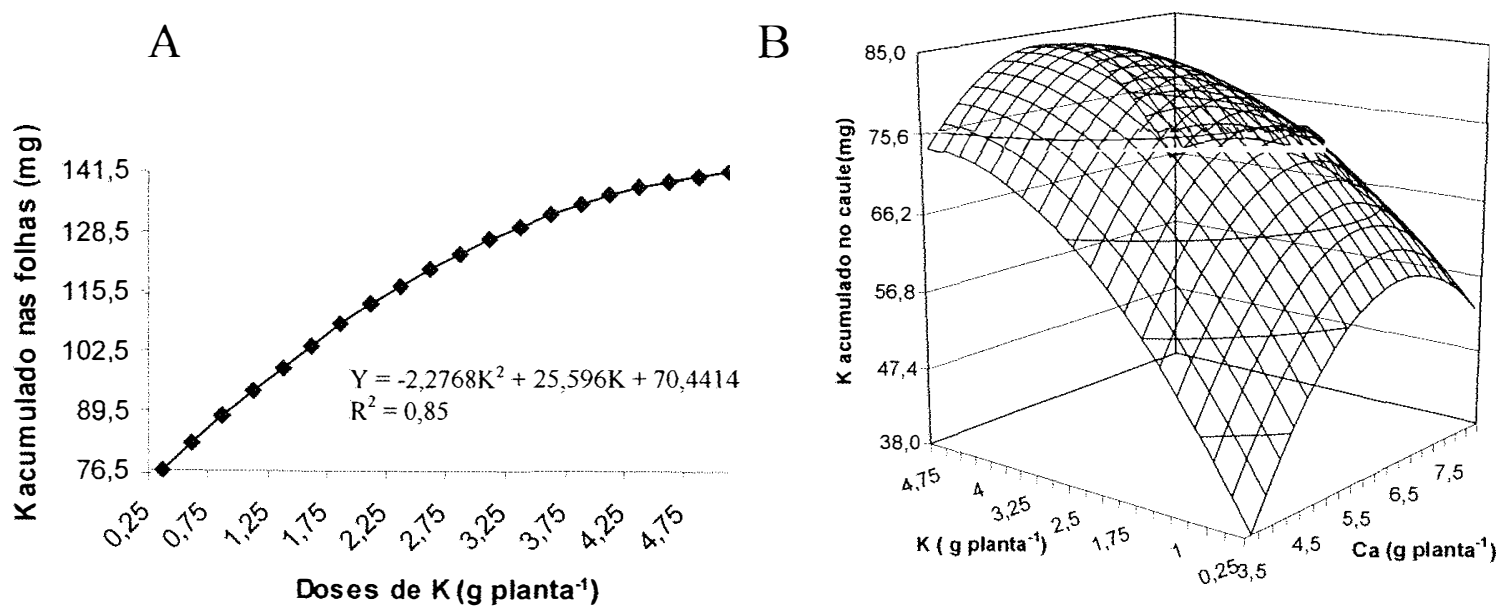

$Y=-1,522 K^{2}+19,357 \mathrm{~K}-2,663 \mathrm{Ca}^{2}+34,233 \mathrm{Ca}-1,088 \mathrm{CaK}-52,998$
$R^{2}=0,70$

$\mathrm{C}$

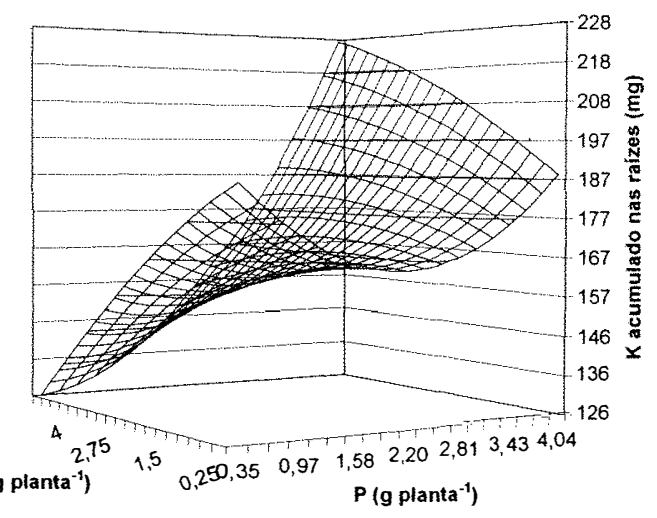

$$
\begin{aligned}
& Y=-0,7896 N^{2}-10,6494 N+6,6673 P^{2}-30,2492 P+5,6919 P N+198,8114 \\
& R^{2}=0,66
\end{aligned}
$$

Figura 16 - Quantidade de K acumulado pelo limoeiro 'Cravo', aos 5 meses após o transplante: folhas (A), caule (B) e raízes (C). 
Houve interação entre $\mathrm{N}$ e $\mathrm{K}$ no acúmulo de $\mathrm{Ca}$ nas folhas do limoeiro 'Cravo', na qual o $\mathrm{N}$ interferiu positivamente $\mathrm{e} \quad \mathrm{O} \quad \mathrm{K}$ negativamente (Figura 17A). Isso poderia ser explicado pela inibição competitiva entre o $\mathrm{K}$ e o $\mathrm{Ca}$, pois como o $\mathrm{K}$ é monovalente, é mais facilmente absorvido pelas plantas, diminuindo dessa maneira a absorção e consequentemente o acúmulo de Ca.

No acúmulo de Ca no caule houve interação entre $\mathrm{N}$ e Ca, com o acúmulo máximo $(0,063 \mathrm{~g}$ de $\mathrm{Ca})$ nas doses de 3,95 e de 6,3 g por planta de $\mathrm{N}$ e de $\mathrm{Ca}$, respectivamente (Figura 17B).

Para o acúmulo total de Ca houve um efeito quadrático entre a quantidade acumulada e as doses de N. O acúmulo máximo foi de 0,276 g de Ca na dose 4,01 g por planta de $\mathrm{N}$ (Figura 17C). As folhas acumularam $43,3 \%$ e o caule $23,1 \%$ do total acumulado de Ca pela planta. 
A
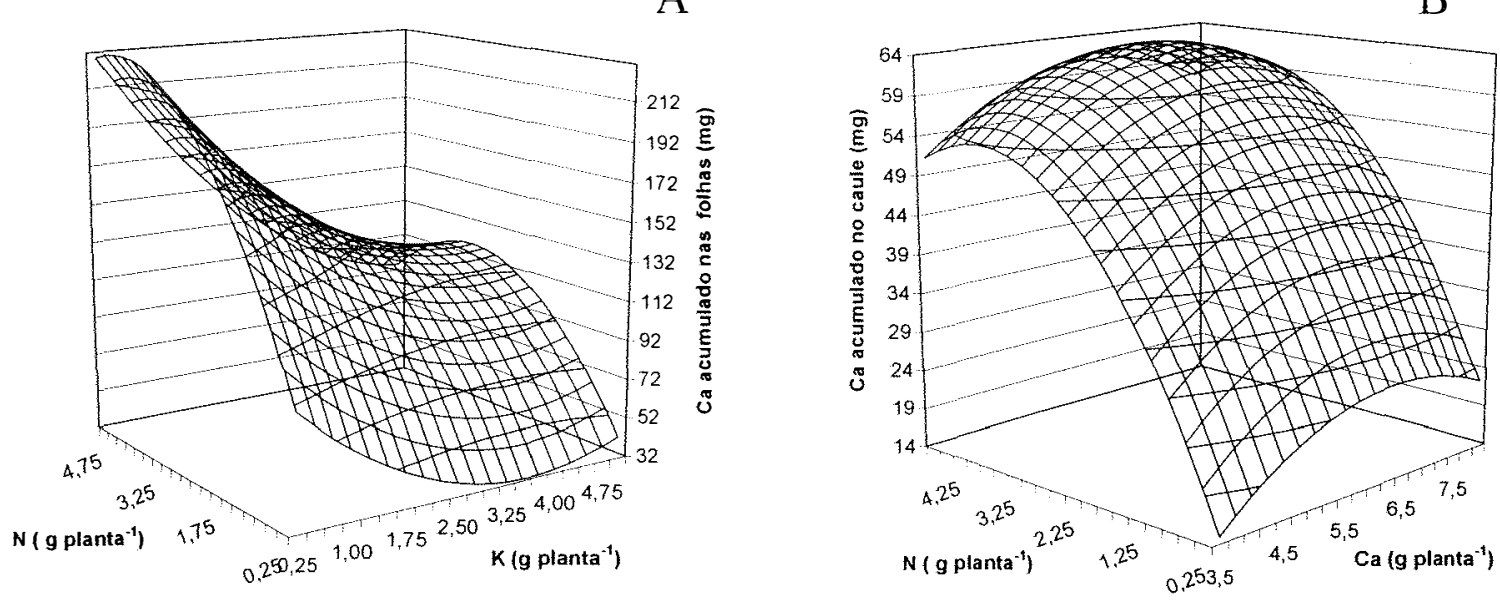

$Y=-8,4156 \mathrm{~N}^{2}+74,127 \mathrm{~N}+5,110 \mathrm{~K}^{2}-35,623 \mathrm{~K}-3,811 \mathrm{KN}+80,129$ $\mathrm{R}^{2}=0,81$

$\mathrm{Y}=-2,7897 \mathrm{~N}^{2}+22,614 \mathrm{~N}-1,284 \mathrm{Ca}^{2}+16,518 \mathrm{Ca}-\bullet, 094 \mathrm{CaN}$

C

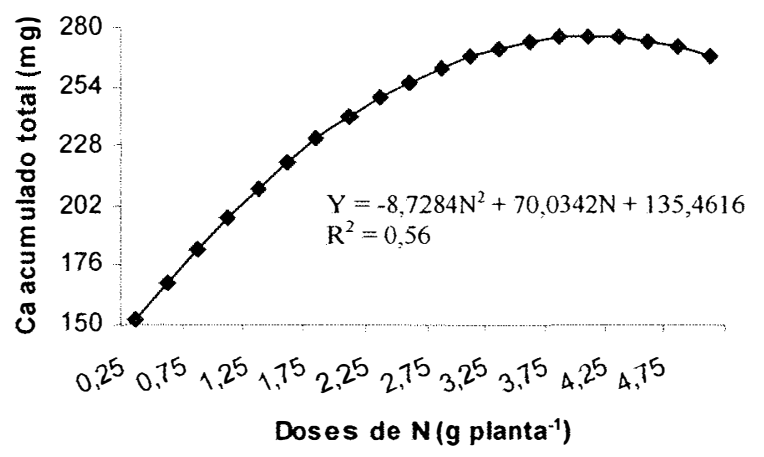

Figura 17 - Quantidade de Ca acumulado pelo limoeiro 'Cravo', aos 5 meses após o transplante: folhas (A), caule (B) e total (C).

Analisando-se o acúmulo de $\mathrm{Mg}$ do limoeiro 'Cravo', observa-se a interação entre $\mathrm{N}$ e $\mathrm{K}$ nas folhas e nas raizes, e entre $\mathrm{N}$ e $\mathrm{P}$ no caule (Figura 18). Nas folhas, o maior acúmulo de $\mathrm{Mg}(0,035 \mathrm{~g})$ ocorreu com a dose 4,23 g por planta de $\mathrm{N}$ e com a dose mínima de K (Figura 18A). 
Nas raízes ocorreu resposta similar, com um acúmulo máximo de 0,022 g de Mg com uma dose de 3,06 g de $\mathrm{N}$ por planta e com uma doses mínima de $\mathrm{K}$ (Figura $18 \mathrm{C}$ ). As doses de $\mathrm{K}$ tiveram um efeito negativo no acúmulo de $\mathrm{Mg}$, provavelmente pelo mesmo motivo que reduziu o acúmulo de $\mathrm{Ca}$. O acúmulo máximo de $\mathrm{Mg}$ pelo caule $(0,023 \mathrm{~g})$ foi obtido com as doses de 3,23 e 2,64 g por planta de $\mathrm{N}$ e de $\mathrm{P}$, respectivamente (Figura 18B).

O somatório do acúmulo de $\mathrm{Mg}$ pela planta foi de 0,081 g, sendo $27,3 \%$ acumulado nas raízes e $72,7 \%$ na parte aérea. 
A

B

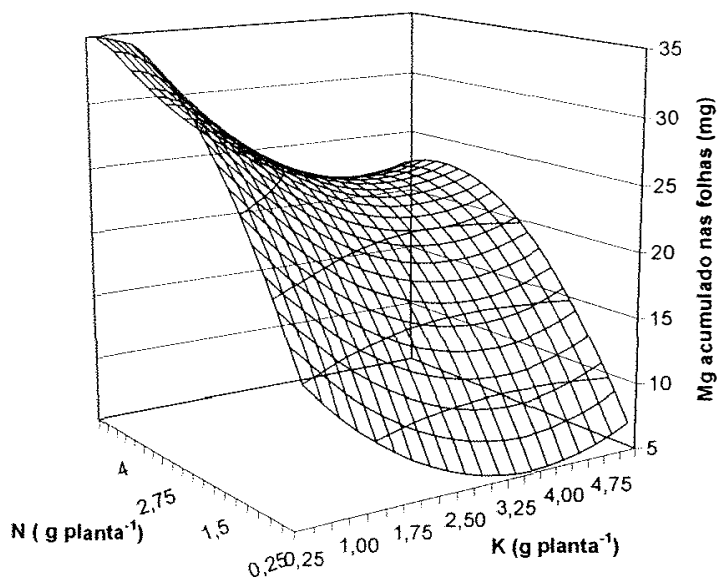

$\mathrm{Y}=-1,0678 \mathrm{~N}^{2}+9,974 \mathrm{~N}+0,9053 \mathrm{~K}^{2}-6,338 \mathrm{~K}-0,231 \mathrm{KN}+14,049$ $\mathrm{R}^{2}=0,87$

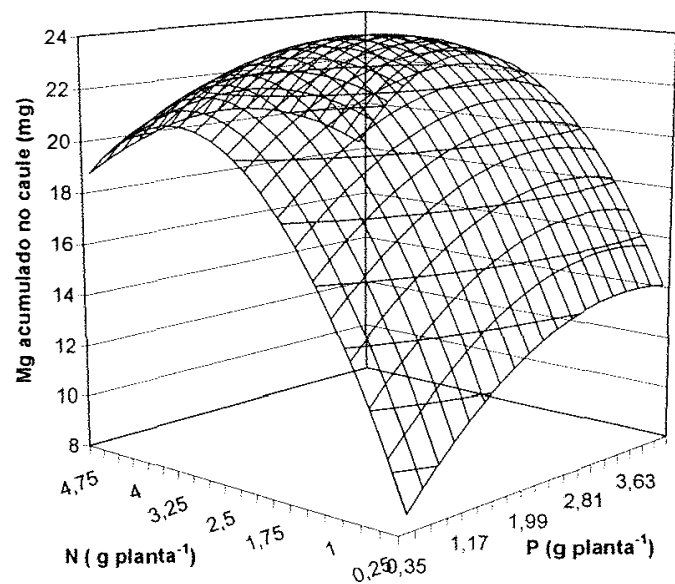

$Y=-1,1074 \mathrm{~N}^{2}+8,052 \mathrm{~N}-0,5741 \mathrm{P}^{2}+4,1 \mathrm{P}-0.339 \mathrm{PN}+5,377$ $\mathrm{R}^{2}=0,85$

C

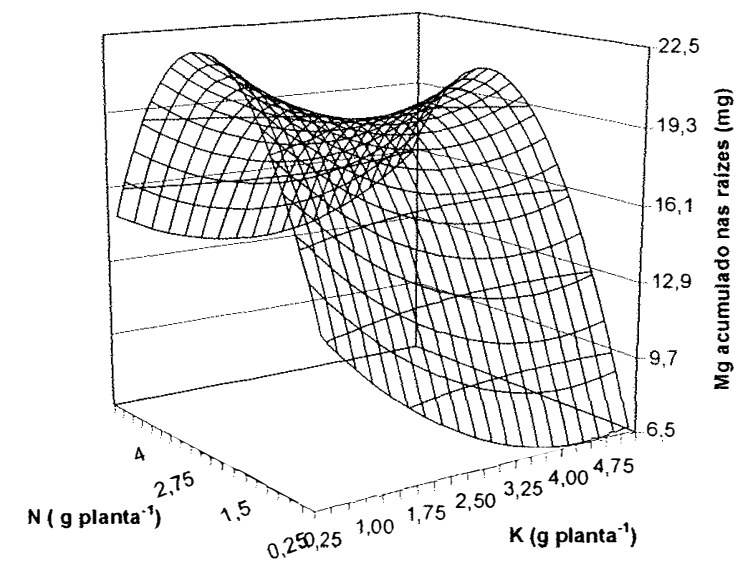

$Y=-1,5176 \mathrm{~N}^{2}+8,229 \mathrm{~N}+0,404 \mathrm{~K}^{2}-3,546 \mathrm{~K}+0,334 \mathrm{KN}+12,0414$

$\mathrm{R}^{2}=0,66$

Figura 18 - Quantidade de $\mathrm{Mg}$ acumulado pelo limoeiro 'Cravo', aos 5 meses após o transplante: folhas (A), caule (B) e raizes (C). 
Para o acúmulo de $\mathrm{S}$ pelas folhas, caule e raízes do limoeiro 'Cravo' houve interação entre N e Ca (Figura 19).

A

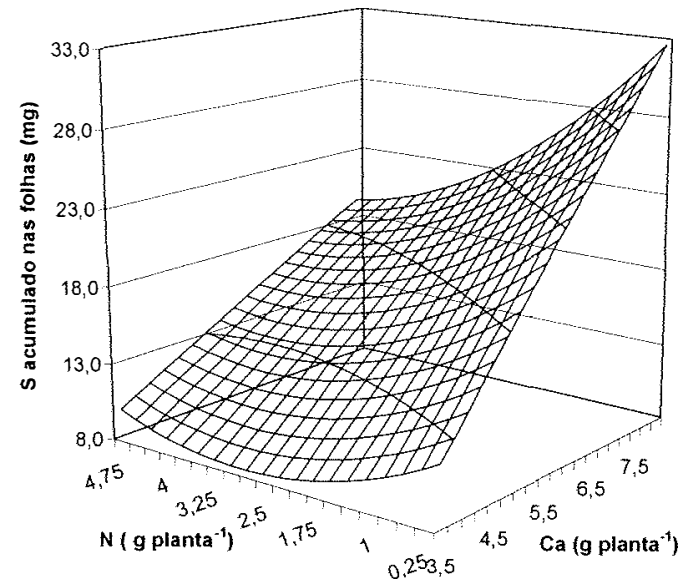

$\mathrm{Y}=0,4617 \mathrm{~N}^{2}-1,013 \mathrm{~N}-0,027 \mathrm{Ca}^{2}+5,066 \mathrm{Ca}-0,531 \mathrm{CaN}-4,819$ $\mathrm{R}^{2}=0,71$
$\mathrm{B}$

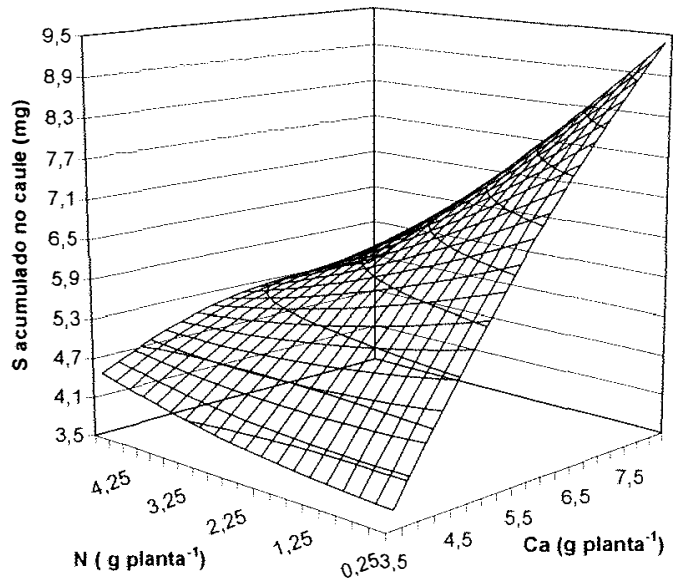

$\mathrm{Y}=0,0246 \mathrm{~N}^{2}+0,811 \mathrm{~N}-0,072 \mathrm{Ca}^{2}+2,138 \mathrm{Ca}-0,228 \mathrm{CaN}-2,839$ $\mathrm{R}^{2}=0,51$

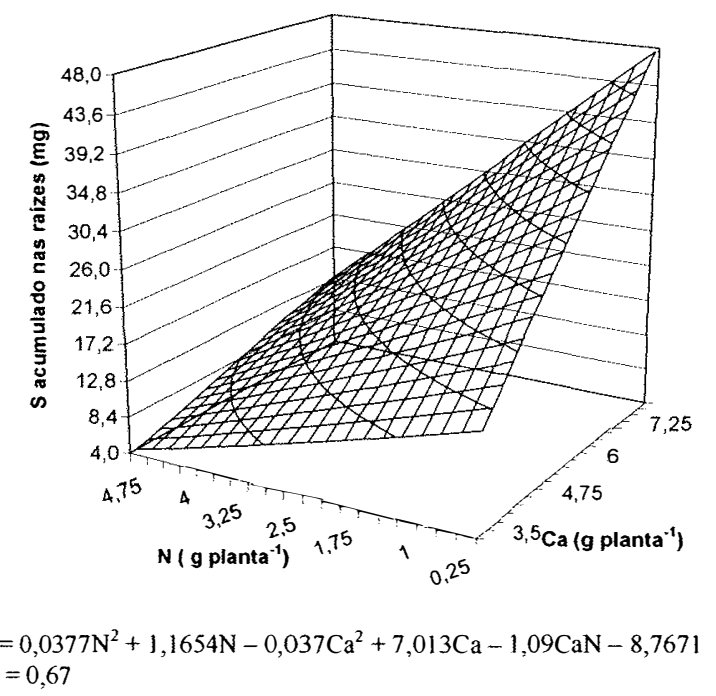

$\mathrm{C}$

Figura 19 - Quantidade de S acumulado pelo limoeiro 'Cravo', aos 5 meses após o transplante: folhas (A), caule (B) e raízes (C).

Em todas as partes da planta ocorreu um efeito negativo das doses altas de $\mathrm{N}$, pois com o aumento dessa quantidade ocorreu uma 
redução na quantidade de S acumulado (Figuras 19 A, 19B e 19C). Entretanto, ocorreu uma interação positiva para o $\mathrm{Ca}$, pois o aumento das doses de $\mathrm{Ca}$ causou um maior acúmulo de $\mathrm{S}$. Esse efeito possivelmente seja devido à fonte de Ca utilizada no experimento (gesso) que possui $\mathrm{S}$.

No acúmulo de S na parte aérea da laranjeira 'Pêra' observa-se a interação entre $\mathrm{N}$ e $\mathrm{K}$, com um acúmulo máximo de 0,065 g de $\mathrm{S}$ nas doses de 6,0 e 1,0 g por planta de $\mathrm{N}$ e de $\mathrm{K}$, respectivamente. Observa-se que o $\mathrm{N}$ demonstrou uma forte tendência linear positiva (Figura 20).

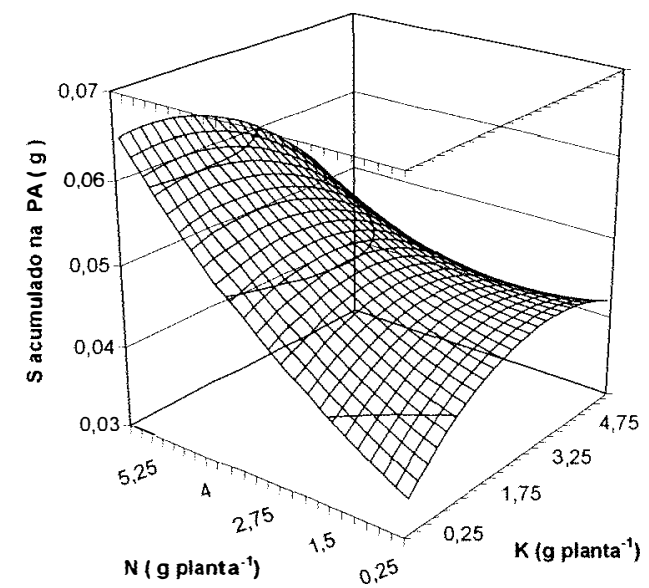

$Y=0,0004 N^{2}+0,003 N-0,0007 K^{2}+0,006 K-0,0008 K N+0,032$
$R^{2}=0,83$

Figura 20 - Quantidade de S acumulado pela laranjeira 'Pêra' na parte aérea, aos 6 meses após a enxertia. 


\section{CONCLUSŌES}

Dos resultados obtidos e dentro dos limites estudados, pode-se concluir que:

Para a produção dos porta-enxertos de limão 'Cravo' as doses que proporcionaram os melhores resultados de produção de material seco total, diâmetro de caule, altura e concentrações foliares nas plantas foram $\mathrm{N}=3,5 ; \mathrm{P}=2,7 ; \mathrm{K}=2,0$ e $\mathrm{Ca}=6,5 \mathrm{~g}$ por planta.

As doses de nitrogênio, fósforo, potássio e cálcio, aplicadas às plantas, não tiveram influência nas concentrações de carboidratos solúveis totais nas folhas.

Para a produção de mudas de laranjeira 'Pêra' as doses que proporcionaram os melhores resultados de produção de material seco total, altura de plantas e concentrações foliares nas plantas foram $\mathrm{N}=$ 5,$0 ; \mathrm{K}=2,0$ e $\mathrm{Ca}=5,0 \mathrm{~g}$ por planta.

Há necessidade de maiores pesquisas com mudas cítricas em vasos pois, a maioria das tabelas de adubação são para plantas adultas. 


\section{REFERÊNCIAS BIBLIOGRÁFICAS}

ANDERSON, C.A. Fruits yields, tree size and mineral nutrition relationships in valencia orange trees as affected by liming. Journal of Plant Nutrition, v. 10, p.1907-1916, 1987.

ARAÚJO, S.C.B. de; SOUZA, M. de. Influência da adubação e vigor dos ramos porta-borbulhas na qualidade dos enxertos de citros. Ciência e Prática, Lavras, v.18, n.2. p.151-157, abr./jun.1994.

BARKER, A.V. Nutritional factors in photosynthesis of higher plants. Journal of Plant Nutrition, v.1, n.3, p.309-342, 1979.

Bernardi, A. C. C.; CARMEllo, Q. A. C.; CARVAlho, S. A. de Desenvolvimento de mudas de citros cultivadas em vaso em resposta à adubação NPK. Scientia Agricola, v.57, n.4, p.733-738, 2000 a.

Bernardi, A. C. C.; CARMello, Q. A. C.; CARVAlho, S. A. de Macronutrientes em mudas de citros cultivadas em vasos em resposta à adubação NPK. Scientia Agricola, v.57, n.4, p.761-767, 2000b.

BERNARDI, A.C. C. Produção em vasos de mudas de Citrus em resposta à adubação NPK em ambiente protegido. Piracicaba, 1999. 108p. Tese (Doutorado) - Escola Superior de Agricultura "Luiz de Queiroz", Universidade de São Paulo. 
BLACK, C. A. Soil-plant relationships. New York: John. Wiley, 1967. $792 \mathrm{p}$.

BRIDGES, D.M.; YOUTSEY, C.O. Cultural practices in Florida citrus nurseries. In: INTERNATIONAL CITRUS CONGRESS, Riverside, 1977. Proceedings. Riverside: International Society of Citriculture, 1977. p. 121-124.

BUENO, D.M.; SOUZA, M. de. Superfosfato triplo para porta-enxertos de citros em diferentes tipos de solos. Pesquisa Agropecuária Brasileira, v.24, n.5, p.527-529, maio. 1989.

CAMARGO, I.V.P. de. SOUZA, M. de.; CARVALHO, J.G.; OlIVEIRA, E. de. Doses e fontes de fósforo e de fungos micorrizicos sobre a nutrição mineral do limoeiro "cravo" até a repicagem. Pesquisa Agropecuária Brasileira, v.25, n.10. p.1465-1470, out.1990.

CARVALHO, S.A. de. Produção de porta-enxertos cítricos, sob doses crescentes de nitrato de potássio. Pesquisa Agropecuária Brasileira, v.29, n.1, p.87-90, 1994a.

CARVALHO, S.A. de. Manejo da adubação nitrogenada na produção de porta-enxertos cítricos em bandejas. Lavras, 1994b. 95 p. Tese (Doutorado) - Escola Superior de Agricultura de Lavras.

CARVALHO, S. A. de. Estratégias para estabelecimento e manutenção de matrizes, borbulheiras e viveiro de citros em ambiente protegido. In: SEMINÁRIO INTERNACIONAL DE CITROS - TRATOS CUlTURAIS, 5., Bebedouro, 1998. Anais. Bebedouro: Fundação Cargill, 1998. p. 67-101. 
CARVALHO, S.A. de; LARANJEIRA, F.F. Protótipo de viveiro de mudas certificadas e borbulheiras sob telado à prova de afideos do Centro de Citricultura-IAC. Laranja, v.15, n.2, p.213-220, 1994.

CARVAlHO, S. A. de.; SOUZA, M. de. Resposta do limoeiro 'Cravo' em sementeira a dois métodos de aplicaçāo do superfosfato simples. In: CONGRESSO BRASILEIRO DE FRUTICULTURA, 9., Campinas, 1987. Campinas: Sociedade Brasileira de Fruticultura, 1988. p.429434.

CARVALHO, S.A. de; SOUZA, M. de Doses e freqüência de aplicaçāo de nitrato de potássio no crescimento do limoeiro 'Cravo' e da tangerina 'Cleópatra' em bandejas. Pesquisa Agropecuária Brasileira, v.31, n.11, p.815-822, 1996.

CASTLE, W.S.; FERGUNSON, J.J. Current status of greenhouse and container production of citrus nursery trees in Florida. Proceedings of the Florida State for Horticultural Society, v.95, p. 42-46, 1982.

CASTLE, W.S.; ROUSE, R.E. Total mineral nutrient content of Florida citrus nursery plants. Proceedings of the Florida State for Horticultural Society, v. 103, p. 42-44, 1990.

CHAPMANN, H.D. The mineral nutrition of citrus. In.: REUTER, V.; BATCHELOR, L.D.; WEBBER, H. (Ed.) The citrus industry. Berkeley: University of California, 1968. p.127-289.

CIPOLLI, J.R. efeitos da aplicaçāo de calcário calcinado, gesso e misturas calcário-gesso na cultura de citros. I. Resultados preliminares. Jaboticabal, 1986. 49p. Monografia (Graduaçāo) Faculdade de Ciências Agrárias e Veterinárias - UNESP. 
COElho, F.S.; Verlengia, F. Fertilidade do solo. 2. ed. Campinas: Instituto Campineiro de Ensino Agrícola, 1973. 384p.

COETZEE, J.G.K.; ESSELEN, L.; VAN ROOYEN, A. Fertilization of nursery trees - alternative method. In: WORLD CONGRESS OF THE INTERNATIONAL SOCIETY OF CITRUS NURSERYMEN. 2., Pietermaritzburg, 1993. Proceedings. Pietermaritzburg: International Society of Citrus Nurserymen, 1993. p.143-150.

CONAGIN, A.; JORGE, J.P.N. Delineamentos (1/5) 533. Bragantia, v.36, n.3, p.23-58, 1977.

CONAGIN, A.; JORGE, J.P.N. Delineamento $(1 / 5)(5 \times 5 \times 5)$ em blocos. Bragantia, v.41, p.155-168, 1982.

FNP CONSULTORIA \& COMÉRCIO. Agrianual 2002: anuário da agricultura brasileira. São Paulo, 2002. p.285-315: Laranja.

FONSECA, E.B.A.; OlIVEIRA, E.; SOUZA, M. de.; CARVALHO, J.G. de. Efeitos do fósforo e fungo MVA na nutrição de dois porta-enxertos de citros. Pesquisa Agropecuária Brasileira, v.29, n.12. p.1889-1896, dez.1994.

FONTANEZZI, G.B.S. Efeitos de micorriza vesículo-arbuscular e de superfosfato simples no crescimento e nutrição de porta-enxertos de citros. Lavras, 1989. 105p. Dissertação (Mestrado) - Escola Superior de Agricultura de Lavras.

FORD, H.W.; REUTHER, W.; SMITH, P.F. Effect of nitrogen on root development of valencia orange trees. Proceedings of the Florida State for Horticultural Society, v.70, p.234-244, 1957. 
FORTES, L de A. Processos de produção de porta-enxerto limoeiro (Citrus limonia Osbeck cv. Cravo) em vasos. Lavras, 1991. 96p. Dissertação (Mestrado) - Escola Superior de Agricultura de Lavras.

GALLO, J.R.; HIROCE, R; RODRIGUEZ, O.R. Correlação entre composição das folhas e produção e tamanho de frutas de laranjeira Baianinha. Bragantia, v.25, n.20, p. 77-88, 1966.

GALLO, J.R.; MOREIRA, S.; RODRIGUES, O.; FRAGA Jr., C.G. Influência da variedade e do porta-enxerto na composição mineral das folhas de citros. Bragantia, v.19, n.20, p. 307-318, abr. 1960.

GAMA, A. M. P. Produção de mudas cítricas. Informe Agropecuário, v.9, n.102, p. 20-47, 1983.

GRAFF, C.C.D.; MARINHO, C.S.; SOUTO, R.F.; PAIVA, L.V.; SOBRINHO, F.S. Efeito da fertilização foliar após enxertia no crescimento e nutrição da muda da laranjeira (Citrus sinensis L. Osbeck cv. Valência). Ciência e Prática, v.18, n.3, p.264-267, jul./set. 1994.

GRUPO PAULISTA DE ADUBAÇÃO E CALAGEM PARA CITROS. Recomendação de adubação e calagem para citros no Estado de São Paulo. Cordeirópolis, 1994. 27p.

HUBER, S.C. Role of potassium in photosynthesis and respiration. In: MUNSON, R.D. (Ed.) Potassium in agriculture. Madison: Soil Science Society of America, 1985. p.369-396.

HUME, H.H. Cultura das plantas citricas. Trad. de J. OSCHERY. Rio de Janeiro: Ministério da Agricultura, Serviço de Informação Agrícola, 1952. 562p. 
JACOBSON, L., MOORE, D.P.; HANNAPEL, R.J. Role of $\mathrm{Ca}$ in a absorption of monovalent cations. Plant physiology, v.35, p.352358. 1960.

KOLLER, O.C. Citricultura: laranja, limāo e tangerina. Porto Alegre: Rangel, 1994. 446p.

KOO, R. C. J. Potassium nutrition of citrus. In.: MUNSON, R.D. (ed.) Potassium in agriculture. Madison: Soil Science Society of America, 1985. p.1077-1086.

KOO, R.C.J.; REESE, R.L. Influence of nitrogen, potassium and irrigation on citrus fruit quality. In: INTERNATIONAL CITRUS CONGRESS, Riverside, 1977. Proceedings. Riverside, International Society of Citriculture, 1977. p.34-38.

LAVON, R.; GOLDSCHMIDT, E.E.; SALOMO R.; FRANK, A. Effect of potassium, magnesium, and calcium deficiencies on carbohydrate pools and metabolism in Citrus leaves. Journal of the American Society for Horticultural Science, v.120, n.1, p.54-58, 1995.

LEOPOLD, A.C. Plant growth and development. New Delly. Mc GrowHill, 1984. 466p.

LIRA, L.M. Efeito de substratos e do superfosfato simples no limoeiro (Citrus limonia Osbeck cv. Cravo) até a repicagem. Lavras, 1990. 85p. Dissertaçāo (Mestrado) - Escola Superior de Agricultura de Lavras.

LOCATELLI, M. Efeito de formas, fontes e doses de N sobre o crescimento e composiçāo mineral de mudas de Eucaliptus grandis W. Hill (ex Maiden). Viçosa, 1984. 64p. Dissertaçāo (Mestrado) - Universidade Federal de Viçosa. 
LOPES, A.S. Manual de fertilidade do solo. São Paulo: ANDA, POTAFOS, 1989. 155p.

MALAVOLTA, E. Elementos de nutrição mineral de plantas. São Paulo: Ceres, 1980. 245p.

MALAVOLTA, E.; VIOLANTE NETTO, A. Nutrição mineral, calagem, gessagem e adubação dos citros. Piracicaba: Associação Brasileira para a Pesquisa da Potassa e do Fosfato, 1989. 153p.

MALAVOLTA, E.; VITTI, G.C.; OLIVEIRA, S.A. Avaliação do estado nutricional das plantas. Piracicaba: POTAFOS, 1997. 319p.

MARSCHNER, H. Mineral nutrition of higher plants. 2.ed. London: Academic Press, 1995. 889 p.

MAUST, B.E.; WILLIAMSON, J.G. Nitrogen rate effect on growth of containerized citrus nursery plants. Proceedings of the Forida State for Horticultural Society, v. 104, p.191-195, 1991.

MAUST, B.E.; WILLIAMSON, J.G. Nitrogen nutrition of containerized citrus nursery plants. Journal of American Society for Horticultural Science, v.119, p.195-201, 1994.

MELLONI, R.; NOGUEIRA, M.A.; FREIRE, V.F.; CARDOSO, E.J.B.N. Fósforo adicionado e fungos micorrizicos arbusculares no cresciemento e nutrição mineral de limoeiro-cravo [Citrus limonia (L) Osbeck]. Revista Brasileira de Ciência do Solo, v.24, p.767-775, 2000.

MENGEL, K.; KIRKBY, E.A. Principles of plant nutrition. 5.ed. Bern: International Potash Institute, 2001. 849 p. 
MILLER, M.H.; MAMARIL, C.P; BLAIR, G.J. Ammonium effects on phosphorus absortion througth $\mathrm{pH}$ changes and phosphorus precipitation at the soil-root interface. Agronomy Journal, v.62, n.4, p. 524-527, july/aug., 1970.

MOURĀO FILHO, F.A.A.; DIAS, C.T.S.; SALIBE, A.A. Efeito da composição do substrato na formação de mudas de laranjeira "Pêra". Scientia Agricola, v.55, n.1, p.35-42, jan./abr. 1998.

NATR, L. Influence of mineral nutrients on photosynthesis of higher plants. Photosynthetica, v.6, p.80-99, 1972.

NEVES, E.M.; BOTEON, M. Impactos alocativos e distributivas na citricultura. Preços Agrícolas, n.132, p.3-6, fev. 1998.

NICOLI, A.M.; SOUZA, M. de. Efeitos do fósforo sobre os teores de macronutrientes do limoeiro "cravo" desenvolvido em vasos. Pesquisa Agropecuária Brasileira, v.21, n.12. p.1253-1256, dez.1986.

PANZANI, C.R.; PRATES, H.S.; GREVE, A. Sistema de produção de muda certificada de citros no Estado de São Paulo. Laranja, v.15, n.1, p.175-199, 1994.

PASSOS, O.S. A citricultura no mundo e no Brasil. Cruz das Almas: EMBRAPA, CNPMF, 1989. 43p. (EMBRAPA-CNPMF. Documento, $30)$.

PAULA, C.M.P. de. Efeito do superfosfato simples e do esterco de galinha na obtenção de porta-enxertos de limoeiro ‘Cravo' para indexação de matrizes. Lavras, 1991. 54p. Dissertação (Mestrado) - Escola Superior de Agricultura de Lavras. 
POOVAIAH, B.W. Calcium and senescencie. In: NOODEN, L.D.; LEOPOLD, A.C. (Ed.). Senescence and aging in plants. New York: Academic Press, 1988. p.359-389.

PORTO, O. M. Influência de métodos de semeadura e de repicagem no desenvolvimento do porta-enxerto de "limoeiro cravo". Piracicaba, 1976. 69p. Dissertação (Mestrado) - Escola Superior de Agricultura "Luiz de Queiroz", Universidade de São Paulo.

QUAGGIO, J.A. Respostas da laranjeira Valência (Citrus sinensis, Osbeck) sobre limão Cravo (Citrus limonia, Osbeck) à calagem e ao equilibrio de bases num Latossolo Vermelho escuro de textura argilosa. Piracicaba, 1991. 107p. Tese (Doutorado) - Escola Superior de Agricultura "Luiz de Queiroz”, Universidade de São Paulo.

REESE, R.L.; KOO, R.C.J. Effect of $\mathrm{N}$ and $\mathrm{K}$ fertilization on leaf analysis, tree size and yeld of three major Florida orange cultivars. Journal of the American Society for Horticultural Science, v.100, p.195-198, 1975.

REITZ, H.J.; KOO, P.C.J. Effect of nitrogen and potassium fertilization on yield, fruit quality, and leaf analysis of 'Valencia' orange. Proceedings of the American Society for Horticultural Science, v.59, p.1-12, 1960.

REZENDE; L.P. Efeito do volume de substrato e do superfosfato simples na formação de porta-enxerto de citros. Lavras, 1991. 97p. Dissertação (Mestrado) - Escola Superior de Agricultura de Lavras. 
REZENDE; L.P.; AMARAL, A.M.; CARVALHO, S.A.; SOUZA, M. Volume do substrato e superfosfato simples na formação do limoeiro 'Cravo' em vasos. I. Efeitos no crescimento vegetativo. Laranja, v.16, n.2, p.155-164, 1995.

ROCHA, M.R. da.; OLIVEIRA, E. de.; CORREAA, G.C. Efeitos de doses de fósforo e fungos MVA no crescimento e nutrição mineral da tangerineira 'Cleopatra' (Citrus reshni Hort ex Tan) em sementeira. Pesquisa Agropecuária Brasileira, v.29, n.5. p.725-721, maio.1994.

RUFTY, T.W.; MACKOWN, C.T.; VOLK, R.J. Alteration in nitrogen assimilation and partitioning in nitrogen stressed plants. Physiologia Plantarum, v.79, p.85-95, 1990.

SARRUGE, J.R.; HAAG, H.P. Análises quimicas em plantas. Piracicaba: ESALQ, Departamento de Química, 1974. 56p.

SAS INSTITUTE. The SAS-system for Windows: release 6.11 (software). Cary, 1996.

SERNA, M.D.; BORRAS, R.; LEGAZ, F.; PRIMO-MILLO, E. The influence of nitrogen concentration and ammonium/nitrate ratio on $\mathrm{N}$-uptake, mineral composition and yield of citrus. Plant and Soil, v.147, n.1, p.13-23, Nov. 1992.

SILVA, D.J. Carboidratos totais não estruturais (CTN). In: SILVA, D.J. (Ed.) Análise de alimentos (métodos químicos e biológicos). Viçosa: Imprensa Universitária, 1981. cap. 13, p.104-109.

SIMÃO, S. Tratado de fruticultura. Piracicaba: FEALQ, 1998. cap.8, p.419-472: Citros. 
SMITH, D. Removing and analyzing total nonstrutural carbohydrates from plant tissue. Wisconsin Agricultural Experiment station Research. v.41, p.1-11, 1969.

SMITH, F.N.; JACKSON, W.A. Nitrogen enhancement of phosphate transport in roots of Zea mays. I. Effects of ammonium and nitrate pretreatment. Plant Physiology, v.84, n.4, p.1314-1318, 1987.

SMITH, P.F. Effect of nitrogen source and placement on the root development of valencia orange trees. Proceedings of the Florida State for Horticultural Society, v.78, p.55-59, 1965.

SMITH, P.F. Citrus nutrition. In: CHILDERS, N.P. (Ed.). Nutrition of fruit crops: tropical, subtropical, temperate tree and small fruits. 3.ed. Somerville: Somerset Press, 1966. v.1, cap. 7, p.174-207.

SMITH, P.F. Calcium requeriments of citrus. Communications in Soil Science and Plant Analysis, v.6, n.3, p.245-260, 1975.

SILVA, D.J. Carboidratos totais não estruturais (CTN). In: SILVA, D.J. (Ed.) Análise de alimentos (métodos químicos e biológicos). Viçosa: Imprensa Universitária, 1981. Cap. 13, p.104-109.

SOUTO, R.F. Métodos de Aplicaçāo e doses do superfosfato simples no limoeiro (Citrus limonia Osbeck cv. Cravo) em viveiro. Lavras, 1993. 75p. Dissertação (Mestrado) - Escola Superior de Agricultura de Lavras.

SOUZA, E.F.O. Efeito de fungos MVA, fontes e doses de fósforo no crescimento do limoeiro 'Cravo', pós-repicagem. Lavras, 1990. 58p. Dissertação (Mestrado) - Escola Superior de Agricultura de Lavras. 
SOUZA, M. de. Nutrição e adubação para produzir mudas de frutiferas. Informe Agropecuário, v.9, n.102, p.40-43, jun. 1983.

SOUZA, M. de. Efeito do P, K e Ca no crescimento da parte aérea da laranjeira 'Pera Rio' (Citrus sinensis (L.) Osbeck) em latossolo vermelho escuro fase cerrado. Piracicaba, 1976. 132p. Tese (Doutorado) - Escola Superior de Agricultura de "Luiz de Queiroz", Universidade de São Paulo.

TENG, Y; TIMMER, V.R. Nitrogen and phosphorus interactions in an intensively managed nursery soil-plant system. Soil Science Society of America Journal, v.58, p.232-238, Jan/Feb. 1994.

VICHIATO M. Influência da fertilização do porta-enxerto tangerineira (Citrus reshni Hort. Ex Tan. cv. Cleópatra) em tubetes, até a repicagem. Lavras, 1996. 82p. Dissertação (Mestrado) - Universidade Federal de Lavras.

VITTI, G.C.; LUZ, P. H. C.; LEÃO, H.C.; SILVA, M.M. Técnicas de utilização de calcário e gesso na cultura do citros. In: SEMINÁRIO INTERNACIONAL DE CITROS, Bebedouro, 1996. Anais. Campinas: Fundação Cargill, 1996. p.131-160.

WILSON, J.B. A review of evidence on the control of shoot:root ratio in relation to models. American Botany, v.61, p.433-449, 1988. 
APÊNDICES 


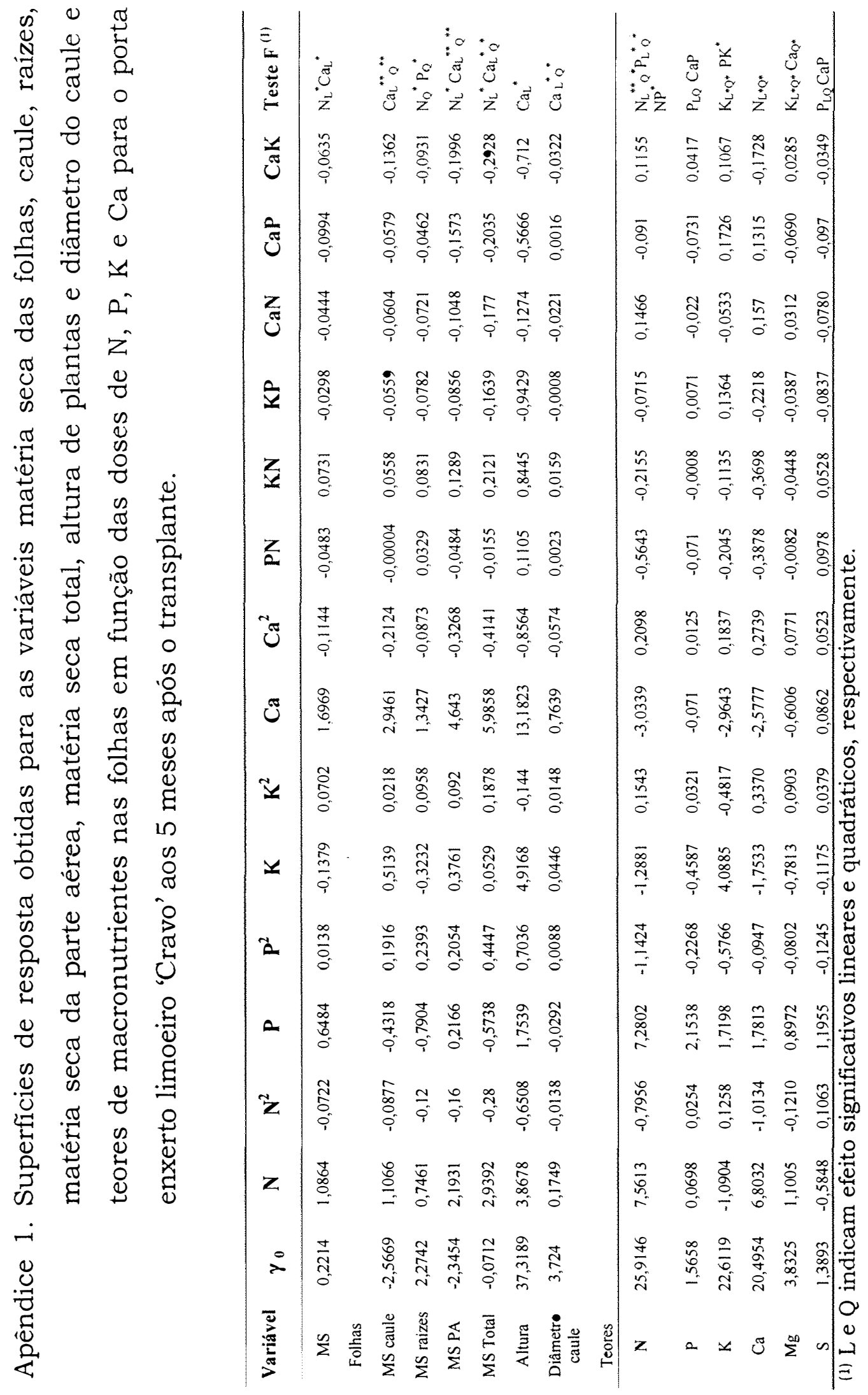




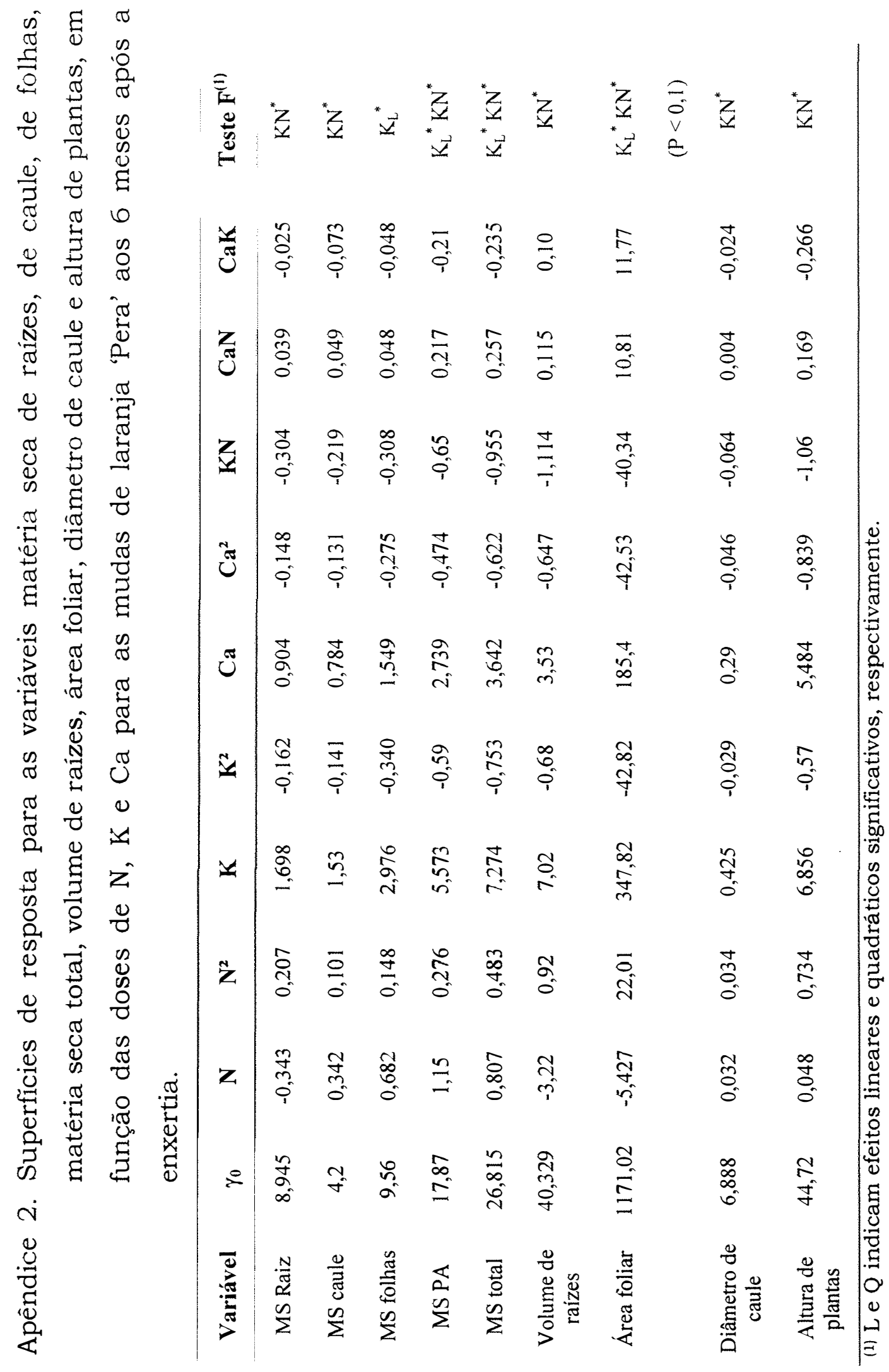




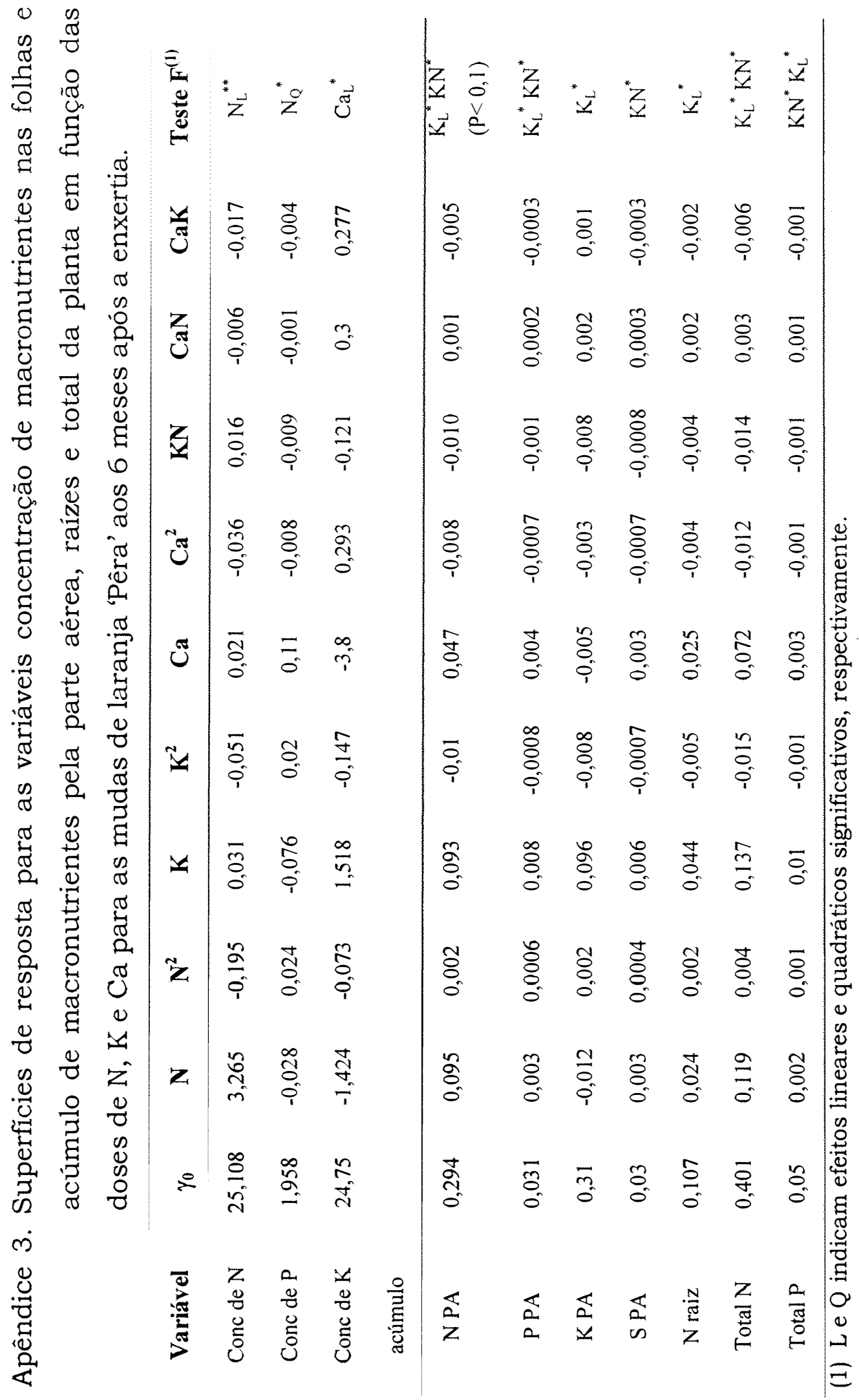

